University of Nebraska - Lincoln

DigitalCommons@University of Nebraska - Lincoln

\title{
Lichens and biofilms: Common collective growth imparts similar developmental strategies
}

Erin C. Carr

Steven D. Harris

Joshua R. Herr

Wayne Riekhof

Follow this and additional works at: https://digitalcommons.unl.edu/plantpathpapers

Part of the Biodiversity Commons, Biology Commons, Other Plant Sciences Commons, Plant Biology Commons, and the Plant Pathology Commons

This Article is brought to you for free and open access by the Plant Pathology Department at DigitalCommons@University of Nebraska - Lincoln. It has been accepted for inclusion in Papers in Plant Pathology by an authorized administrator of DigitalCommons@University of Nebraska - Lincoln. 


\title{
Lichens and biofilms: Common collective growth imparts similar developmental strategies
}

\author{
Erin C. Carr, ${ }^{1}$ Steven D. Harris, ${ }^{2,3,4}$ \\ Joshua R. Herr, ${ }^{1,3,4}$ and Wayne R. Riekhof ${ }^{1}$
}

1 School of Biological Sciences, University of Nebraska-Lincoln, Lincoln, NE 68588, USA

2 Department of Biological Sciences, University of Manitoba, Winnipeg, Manitoba R3T 2N2, Canada

3 Department of Plant Pathology, University of Nebraska-Lincoln, Lincoln, NE 68583, USA

4 Center for Plant Science Innovation, University of Nebraska-Lincoln, Lincoln, NE 68588, USA

Corresponding author - E. C. Carr, University of Nebraska-Lincoln, 1901 Vine St., Room E136, Lincoln, NE 68503, USA;

email erin.creasey@huskers.unl.edu or erin.carr1216@gmail.com

\begin{abstract}
Lichens are traditionally defined as a symbiotic relationship between fungi and algae and/or cyanobacteria. This union forms a unique structure called the thallus, which attaches to surfaces such as rocks and tree bark. Recent reports challenge the view that lichens are comprised of one fungus and one photobiont, and instead suggest that they are a consortium of microbes. Much of lichen biology remains unknown as most of our knowledge of lichens is limited to morphological characteristics with little to no functional analysis of lichen genes. However, lichens and biofilms share many similar physiological traits which when compared may assist in our understanding of lichens. Similarities between the two are rooted in their lifestyle, where
\end{abstract}

Published in Algal Research 54 (2021) 102217

doi:10.1016/j.algal.2021.102217

Copyright (c) 2021 Elsevier B.V. Used by permission.

Submitted 1 October 2020; revised 22 January 2021; accepted 23 January 2021. 
these microbes and their extracellular products attach themselves to a surface and grow in a community structure. Biofilms and lichens alike have distinct features that allow for their lifestyle and identification, such as specific developmental patterns, formation of an extracellular matrix, and their ability to resist abiotic stressors. We argue here that one can gain insight into the cellular processes and evolutionary origins of lichens, which are currently undetermined, by applying knowledge gleaned from studies on microbial biofilms, with a particular focus on fungal biofilms.

Keywords: Lichen, Biofilm, Extracellular matrix (ECM), Fungi, Fungal biofilm, Microbial development

Abbreviations: ECM, extracellular matrix; QSM, quorum sensing molecules; UV, ultraviolet; SEM, scanning electron microscopy; TEM, transmission electron microscopy; Acyl-HSL, acyl-homoserine lactones.

\section{Introduction to lichens and biofilms}

The lichen lifestyle represents over half of all Ascomycetes with theoretically five evolutionary origins of the lifestyle amongst fungi, which makes this fungal form a highly successful yet still confounding entity [1,2] (Fig. 1). Lichens have been observed by scientists and used for medicinal purposes and dyes since ancient times - they were even studied by Aristotle [4]. Since their initial discovery our understanding of lichens has drastically altered and is still changing today. Lichens were originally described and recognized as plants. However, in 1867, Herman Schwendener proposed that lichens were instead a conglomerate of fungi (the mycobiont), and algae or cyanobacteria (the photobiont/ phycobiont and cyanobiont respectively) [9] (Fig. 2). Until recently this was the reigning paradigm of lichen symbiosis, but with the advent of modern sequencing technologies we have amended our understanding of what constitutes a lichen. Researchers are now beginning to understand that lichens do not contain just two organisms or "partners", but rather an entire consortium of microbes, which can even include bacteria and archaea [10-14]. As these developments have only been made in the past 10 years, many scientists are still under the assumption that lichens contain only the mycobiont and the photobiont. A shift in the accepted definition of a lichen to encompass a wider array of organismal participants is slowly gaining acceptance, but more research is needed to characterize the involvement of bacteria and other 
microbes in the lichen symbiosis before a consensus is reached. Presently, no published research characterizes the roles of the other microbes found in lichens, therefore we still know very little about how these organisms are involved in the lichen symbiosis and interact to form a uniquely complex 3-D structure.

Lichens are extremely difficult to grow, maintain, and study in a laboratory setting, growing extremely slowly compared to other microbes, with some slow growing lichens growing only $0.01-0.33 \mathrm{~mm}$ in a year $[15,16]$. Whereas faster lichens can cover up to $64 \mathrm{~mm}$ a year, most lichens fall between those growth extremes [15,17]. Reasons for their slow growth remain enigmatic, but many researchers have attempted to understand this phenomenon. Past and current hypotheses have relied on modeling to determine growth rate factors, with multiple factors having been tested $[15,18]$. It is currently thought that growth rate is limited by the ability for lichens to both shuttle around nutrients, such as carbohydrates, and the rate at which carbon dioxide is taken up for photosynthesis to occur $[18,19]$. These, and possibly other factors that contribute to the slow growth of lichens, remain issues that confront those who study these unique symbioses.

Additionally, the diverse polyphyletic evolutionary origins of lichens (Fig. 1) coupled with the availability of multiple prospective partners within a given "species", contributes to their enigmatic nature $[1,20]$. Lichens are classified based on several features, but typically the photobiont taxon and structural morphology of the thallus provides the basis for classification of a lichen type, such as Xanthoria parietina, which is a Trebouxiod foliose type lichen. While the taxon name given to the lichen is also given to the mycobiont (or vice versa), for example: Endocarpon pusillum the lichen with the mycobiont species Endocarpon pusillum and photobiont species Diplosphaera chodatii. Phenotypic plasticity can then lead to unnecessary taxonomic separation and confusion in understanding lichen biology and diversity. Lichens that contain multiple photobionts (or mycobionts), and promiscuous lichens that can choose between multiple partners further increases confusion in nomenclature. Examples of phenotypic specificities leading to nomenclature issues include: recent indications that some lichens contain multiple fungal partners (ascomycete and basidiomycete) that are required for lichen speciation [8,21], mycobionts that 


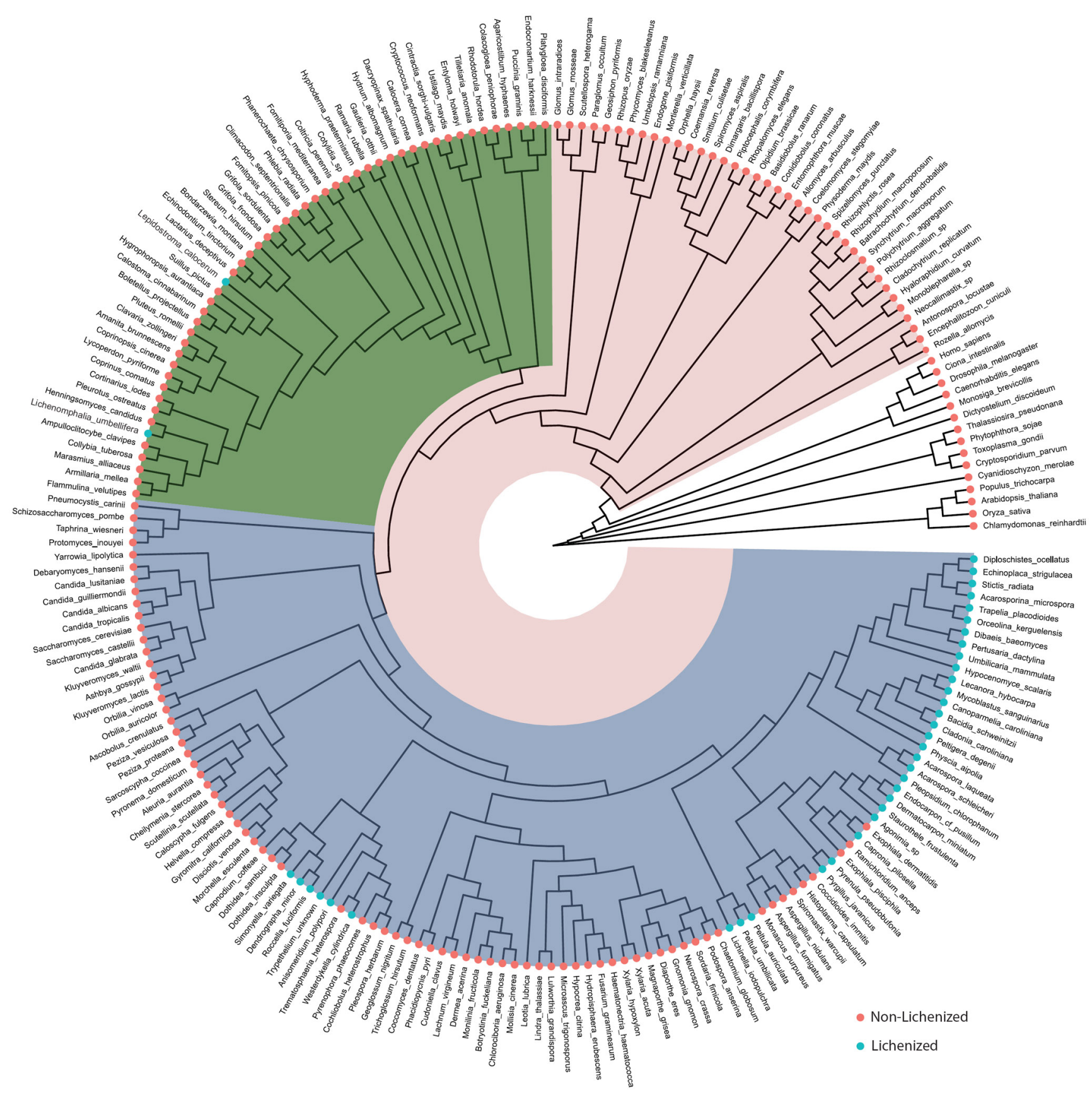

Fig. 1. Phylogenetic tree of the fungal lineages that have developed the lichen form. Tree was constructed with data derived from Hibbett et al. [3] of 23 single copy genes derived from whole genome sequences. The morphology of lichen habit was mapped across the fungal phylogeny. The complete Fungal lineage is represented in the pink portion of the tree, with the green wedge representing the Basidiomycete lineage, and the blue portions representing Ascomycete fungi. 


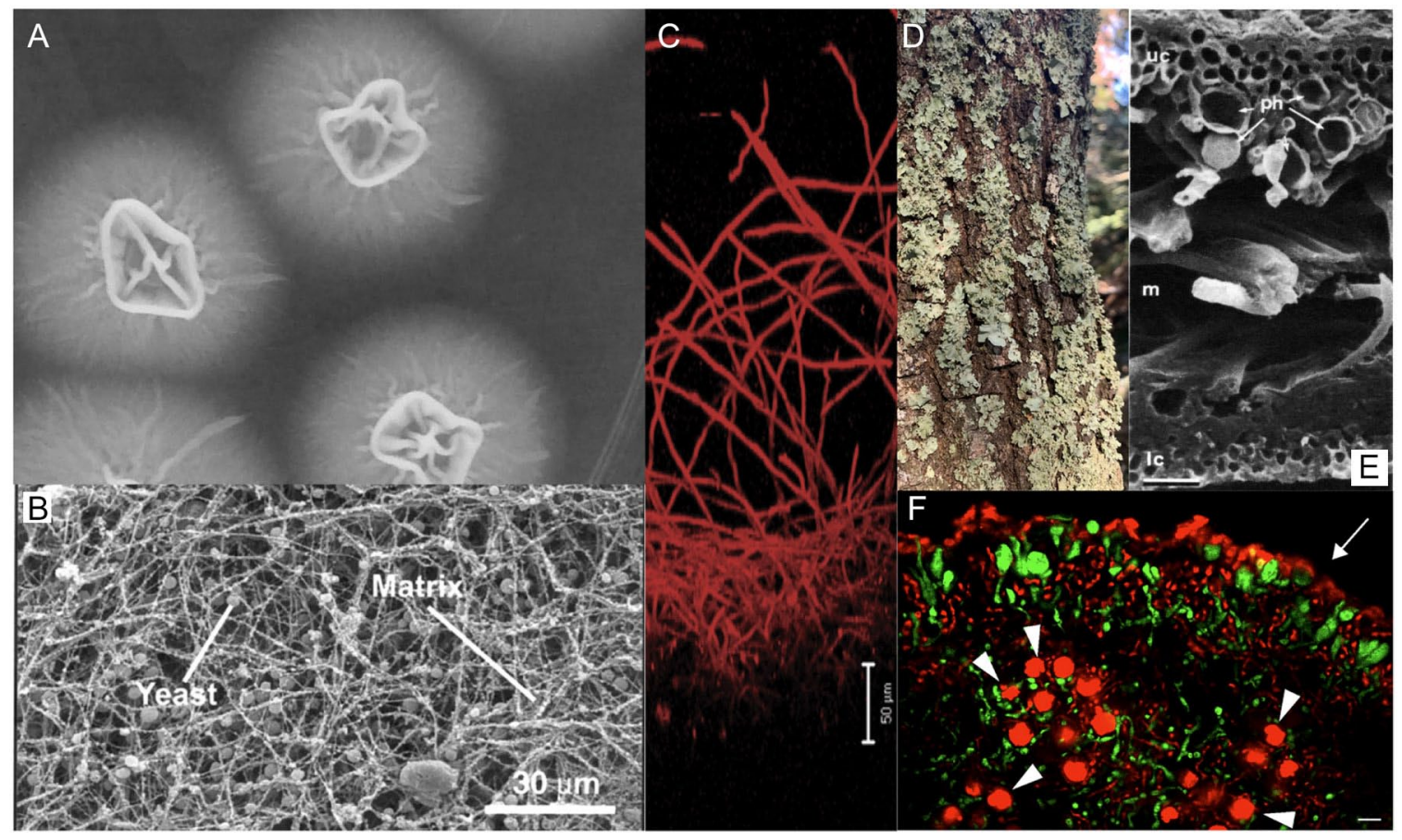

Fig. 2. Photographic and microcopy images of different details of biofilms and lichens. (A-C) Biofilm images of the fungus Candida albicans. A) Photo of a C. albicans colony/biofilms with inner hyphal layer and outer yeast layer (credit: Surabhi Naik). B) SEM photo of C. albicans biofilm, showing hyphal cells, yeast cells, and matrix that forms around the entire biofilm [5]. C) Fluorescent image of the cross section of a C. albicans biofilm [6]. A dense layer of hyphae and yeast is seen on the bottom, and a looser layer of hyphae protrude out the top. (D-F) Images of various lichens. D) A photograph of the lichen Parmotrema sp. on a Live Oak tree in central Florida (credit: Erin Carr) E) SEM of a cross section of the lichen Xanthoria parietina [7]. Uc = upper cortex; $\mathrm{ph}=$ photobiont; $\mathrm{m}=$ medullary thalline layer; $\mathrm{lc}=$ lower cortex. F) Fluorescent cross section of lichen thallus of Letharia vulpina [8]. Arrow is pointing to autofluorescence and the arrow heads are pointing to the algal photobionts below the upper cortex.

are capable of associating with a variety of photobiont partners [22$24]$, and lichens that can contain more than one photobiont simultaneously $[25,26]$. For the sake of simplicity, lichen features and descriptions referred to here will be broad and not specific to any particular lichen morphotype and may not represent all lichen taxa. This diversity of life history strategies has also caused the understanding of lichens to lag behind those of other organisms, but more recent nucleotide sequencing technologies have helped further our knowledge of 
these communities. In order to understand the life history of lichens it is appropriate to make sense of their biology by focusing on the fact that they exist in a similar fashion to microbial biofilms.

Biofilms are defined as an aggregation of microbes and their extracellular products attached to a surface (visual examples in Fig. 2) [27]. This simple, overarching definition is widely accepted by microbiologists, which deconvolutes the study of this microbial form. In a laboratory setting, such as in a petri dish or shaking flask, microbes are typically grown in monoculture under conditions that are not conducive to biofilm formation, although many argue that a simple colony could be a biofilm [28-30]. While some microbes may still form biofilms at the air-liquid interface of shaking flasks, they are more notable in stable ecosystems where biofilms attach to surfaces such as rocks, fermentation tanks, PVC pipes, soil, plant roots, teeth, etc. [31]. Growth on surfaces is only capable due to formation of a biofilm, and therefore it is assumed that all microbes form biofilms in their natural habitats at some point [31,32]. Much research on biofilms has been invested into those that cause diseases or possess the ability to disrupt and destroy man-made structures (walls, plumbing, statues, etc.), with little work devoted to non-destructive biofilms. Because of their broad impacts on human welfare, there has been a lot of research on the genetics and molecular basis of biofilm formation, which stands as a stark contrast to our relatively poor understanding of thallus development in lichens. To date, a small number of lichen mycobiont genomes have been sequenced and only a few have been transcriptionally analyzed [33-36]. Due to this lack of knowledge, our understanding of exactly how lichens form is unknown. However, a comparison of the similarities between lichens and biofilms may facilitate the generation of hypotheses for the establishment and function of the multi-species lichen consortium.

Following the definition of a biofilm, lichens represent one of the most successful surface-attached microbial symbiotic architectures covering $8 \%$ of total land surface on Earth [2]. One could even posit that lichens began as biofilms, and through millions of years of coevolution with symbiotic partners [37], developed into the highly coordinated and more permanent lichen thallus. However, our understandings of the lichen symbiosis and biofilms as a microbial phenomenon have been historically realized via different fields of study and, as a 
Table 1 Similar features between biofilms and lichens.

\begin{tabular}{|c|c|c|}
\hline Feature & Fungal biofilm & Lichen \\
\hline Surfaces adhered to & Hydrophobic; nonpolar; rough & Hydrophobic; rough \\
\hline Stages of development & $\begin{array}{l}\text { Adherence to surface, cell communication } \\
\text { and differentiation, matrix and microniche } \\
\text { formation, dispersal }\end{array}$ & $\begin{array}{l}\text { Adherence to surface, cell communication } \\
\text { and differentiation, matrix formation } \\
\text { and tissue development, dispersal }\end{array}$ \\
\hline Cell differentiation & Microniches; Interstitial voids; sporulating & $\begin{array}{l}\text { Layered tissue differences: upper and lower } \\
\text { conglutinate cortexes, medullary thalline } \\
\text { layer, algal layer, sporulation structures } \\
\text { and vegetative propagules }\end{array}$ \\
\hline Cell interactions & $\begin{array}{l}\text { Synergies between metabolically linked } \\
\text { organisms; antagonism between } \\
\text { non-matching QSM }\end{array}$ & $\begin{array}{l}\text { Syntrophy between mycobiont and } \\
\text { photobiont }\end{array}$ \\
\hline Extracellular matrix & $\begin{array}{l}\text { Generally Hydrophilic with hydrophobic } \\
\text { coating; Known to contain: Hygroscopic } \\
\text { Polysaccharides, eDNA, lipids, and proteins }\end{array}$ & $\begin{array}{l}\text { Hydrophilic with hydrophobic coating; } \\
\text { Known to contain: Hygroscopic } \\
\text { Polysaccharides, and proteins; } \\
\text { potentially eDNA }\end{array}$ \\
\hline Stress resistances & Antimicrobials, UV, desiccation, metal toxicity & $\begin{array}{l}\text { UV, desiccation, metal toxicity, extreme } \\
\text { temperatures }\end{array}$ \\
\hline
\end{tabular}

result, available information regarding these two biological entities differs despite the many connections that can be made. In this review, we will reflect on similarities and differences between biofilms and lichens by focusing on perhaps the three most important aspects of a biofilm and lichens: (1) the development and microbial interactions of microbial communities; (2) the extracellular matrix (ECM) structure and function; and (3) the role of community growth in resistance to abiotic factors (summarized in Table 1). We will also discuss how lichens may be analogous to biofilms due to potential evolutionary origins and identify gaps of knowledge in both phenomena that will help link our understandings of these ecologically and economically important microbial communities.

\section{Microbial development and interactions in biofilms}

\subsection{Stages of development}

Stages of biofilm development have been extensively described in many microorganisms, meaning we now have mostly complete 
models of the genetic cascade involved in forming microbial biofilms $[38,39,46]$. The same cannot be said for lichens. Our knowledge of lichen thallus development relies heavily on re-synthesis experiments-observations of the separation and re-constitution of the mycobiont and photobiont. These experiments have mostly employed scanning electron microscopy (SEM) and transmission electron microscopy (TEM) to characterize the changing morphology of the two partners and their interactions in forming the lichen thallus $[7,9,20,40-45]$ (Fig. 2). In 1993, a model for lichen formation was proposed by Honegger using morphological data, which has been widely adopted. But we can build upon this work by delving into the literature of the cellular processes involved in biofilm formation, particularly in the fungi Candida albicans and Aspergillus fumigatus. We can then hypothesize and more readily focus lichen research on biofilm-specific genes for example, that likely have led to the same biological phenomena in lichen thallus formation.

Biofilm development follows four main stages: 1) adherence, 2) initiation, 3) maturation, and 4) dispersal [32,46]. Each stage has specific microbial requirements and genetic switches, which change between stages of formation [39]. These stages resemble those of lichen thallus development as described in the literature on morphological succession of lichenization. According to Honegger [7], the stages of lichenization are: 1) non-specific contact and recognition, 2) pre-thallus formation, 3) thallus stratification, and 4) mature thallus reproduction and dispersal (Fig. 3). Although the terminology may differ between the developmental stages of biofilms and lichens, the biologically significant processes are aligned across the four stages. The first stage includes adherence to the surface, or to the partner in the lichen literature, and identifying neighboring organisms. The second stage involves a switch in the type of cell growth. The third stage is the differentiation of cell morphotypes and matrix formation. The final stage is dispersal of cells via spores or vegetative propagules. Notably, the time it takes the cells to go through each stage varies significantly between these communities. Lichens take years to grow, whereas some biofilms take only hours. Regardless of the timescale, these two communities share great biological similarities in each stage of their development (Fig. 3). 


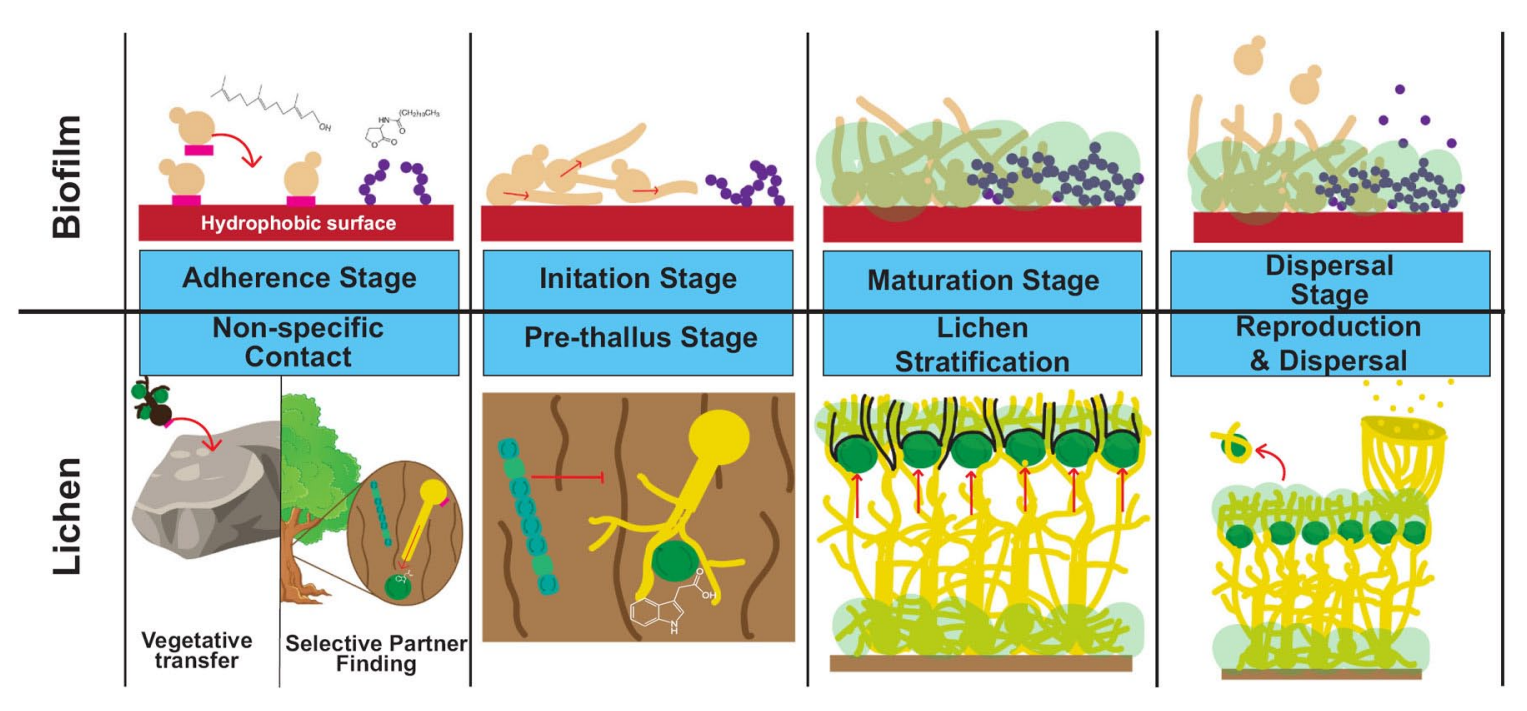

Fig. 3. Summary of the stages of development of biofilms, represented by Candida albicans (tan) and Streptococcus gordonii (purple), and lichens with the mycobiont Xanthoria parietina in yellow and the photobionts in green (algae and cyanobacteria). Adherence and Non-specific contact stage are the first stages of biofilm and lichen development respectively. Both are known for the binding of cells to a hydrophobic surface (rock, bark, or catheter tube) via various hydrophobic proteins represented with a pink rectangle. Initiation and Pre-thallus stages are the second stages of development. This stage is linked to cell differentiation, where $C$. albicans initiates the switch into hyphal growth, and mycobionts initiate hyphal branching. The third stages are the maturation stage and the lichen stratification stage. In these stages both biofilms and lichens create differential zones of cells and form their extracellular matrix. Biofilms form microniches which lead to microcolonies, and interstitial voids which allow for some gas exchange. Lichens separate into 3 main sections the upper cortex where the majority of ECM is contained and the photobiont cells are positioned right below, the medullary thalline layer that is thought to be made up of mostly air or unknown substances $[11,44,47]$, and the lower cortex layer which is considered to also have ECM and is responsible for lichen-surface attachment. The final stage is the dispersal stage, or reproduction and dispersal in lichens. This stage can be caused by reproduction or vegetative release of cells by external disturbance or intent by the community.

\subsection{Adherence/non-specific contact stage}

Biofilm formation begins with the adherence stage. For both bacteria and fungi, this stage consists of "pioneer cells" that adhere to a surface and seed biofilm formation. Surface types that many biofilms adhere to are typically hydrophobic and non-polar, such as 
silicone [27]. This is mostly due to the nature of structures that aid in adhesion to surfaces, which are typically hydrophobic in nature $[31,48,49]$ (Fig. 3). In bacteria this phenomenon is typically initiated by type IV pili, flagella, fimbriae, hydrophobins, and adhesin proteins [31]. Most fungal species that form biofilms do not contain flagellar-like structures, and instead rely on adhesins, hydrophobins, agglutinin-like sequence proteins, and other proteins for their adherence step $[46,50]$.

Akin to monotypic fungal biofilms, lichens also readily attach to hydrophobic surfaces such as rock surfaces, tree bark, and leaves, all of which can present a hydrophobic point of attachment for a lichen spore or propagule, however their mechanism of adherence is poorly understood. One confounding issue with lichen adherence and their nonspecific contact stage is the variety of ways that lichen taxa disperse their cells. While many lichens disperse via vegetative means with both mycobiont and photobiont traveling together (for example, soredia and isidia), there are a number of well-known spore-forming lichens which disperse the mycobiont spores alone [51] (Fig. 3). This variety in dispersal methods likely results in diverse attachment modes based on the "preferred" method of dispersal and attachment surface for given lichen taxa. Since vegetative propagule dispersal contains a pre-established symbiosis composed of mycobiont and photobiont cells, it is likely that these structures rely on fungal proteins for adhesion that might be similar to those that underlie adhesion of biofilm constituents.

One prevailing feature of most Ascomycete spores and particularly those of biofilm-forming Aspergillus spp. is their hydrophobic outer layer. This layer contains hydrophobins that together form a rodlet layer surrounding the spores' matrix [52-55]. This rodlet layer allows for the spores to attach to hydrophobic surfaces to begin forming colonies then, biofilms. Similarly, Magnaporthe spp. also use hydrophobins on their spore surface to attach to hydrophobic plant cuticles $[56,57]$. Without their hydrophobic surface outside of the matrix layer, it has been shown many times that both Aspergillus spp. and Magnaporthe spp. are severely reduced in adhesion to their substrates $[54,56,57]$. Lichens are reported to use similar types of hydrophobic proteins, particularly the class I hydrophobins XEH1 and XPH1, for interactions between the mycobiont and their photosynthetic partners, 
and theoretically also surfaces $[58,59]$. Hydrophobins surround the outside of the extracellular matrix that encompasses the mycobiont and photobiont, as seen by the distinct rodlet layer produced by the hydrophobin proteins, which can only be observed through freezeetch electron microscopy $[41,171]$. No cytological studies, particularly no electron microscopy studies, have been performed on the spores of lichens, therefore we cannot be sure if their spores also contain the distinctive hydrophobin rodlet layer of other Ascomycete spores. However, since the alternative method of lichen reproduction is via vegetative structures directly derived from lichen thalli, it seems reasonable to speculate that the hydrophobic layer surrounding the ECM plays a role in surface adhesion similar to that of fungal biofilms and fungal spores $[58,60]$. Once fungal biofilm cells have bound to their substrate it has been observed that the hydrophobicity of the cells decreases and they instead become hydrophilic [61]. This observation is linked to multiple instances of germinating sporelings of both lichens and biofilm-forming fungi creating or possibly exposing their hydrophilic polysaccharide ECM [61-65]. This shift in hydrophobicity allows for the success of the next step in biofilm and lichen formation, which is characterized by binding to other cells.

\subsection{Initiation/pre-thallus stage}

The second stage of biofilm formation is the initiation stage, which includes cell differentiation, cell-cell adhesion, and filamentation in fungal biofilms specifically [46]. During this stage, the ability to adhere is vital to forming a cohesive biofilm of cells adhering to other cells. Therefore, many times there is less of a distinct separation of the adherence stage from the initiation stage, which is indicated by similarly important genes being expressed and the continuing functional role of adhesion proteins [46]. For lichens this cell-cell adhesion step is required for mycobiont-photobiont interactions (Fig. 3). This step is called the pre-thallus stage in lichen formation and is critical for the ability of mycobionts to engage with prospective photobionts. However, if the lichen reproduces via vegetative propagules then the photobiont and mycobiont travel as a unit and therefore do not require partner recruitment, which presumably leads to quicker lichen development that "skips" the pre-thallus stage [7]. 
Complete coherence between the mycobiont and photobiont is a result of the surface layer hydrophobins of the fungal extracellular matrix encompassing cells of both the photobiont and mycobiont [20]. Two Class I hydrophobin proteins of fungal origin are involved in adherence between mycobiont and photobiont cells in the lichens Xanthoria parietina and $X$. ectaneoides; the proteins are $\mathrm{XPH} 1$ and $\mathrm{XEH} 1$ respectively [58]. These proteins make up the distinctive rodlet layer that surrounds these lichens' ECM within certain structures, similar to other fungal rodlet layers [58]. Timing of photobiont-mycobiont adherence is not entirely understood but is observed to occur very early in the pre-thallus stage, or the late non-specific contact stage [65]. Cell-cell adherence in fungal biofilms has not been fully characterized either, but this is the result of the complicated nature of binding through a variety of mechanisms. Fungal cell-cell adherence has been said to be mediated by GPI-linked adhesin proteins $[6,66,67]$, hydrophobins [52], and polysaccharides of the ECM [68,69], with hydrophobins possibly not playing a role in certain species. In C. albicans biofilm formation, cell-cell adherence is triggered by a switch from yeast growth to hyphal growth, and involves key genes, such as epa 1, hwp 1, and als 1/3. These genes encode GPI-anchored adhesin proteins, which aid in cell-cell adherence and cell-surface adherence in C. albicans $[6,46,66,67]$. The filamentous fungus Aspergillus fumigatus has also recently been identified as a biofilm forming fungus. Aspergillus fumigatus biofilms were initially thought to use hydrophobins like RodB for cell-cell adherence [68]. However, after a full deletion screen of hydrophobin-coding genes, it was determined that hydrophobins are not used for cell-cell adherence in A. fumigatus [70]. On the other hand, deletion of rodA in Aspergillus nidulans revealed a decrease in cell-cell adherence, likely due to nucleation effects and species-specific processes [52]. In lichens, it has been observed that both spore-initiated and vegetative starting structures contain ECM and secrete more once attached to their substrate [65]. Beyond this observation not much is known about mycobiont-mycobiont cell adherence. Nevertheless, the ability of biofilm-forming fungi to utilize adhesin proteins for cell-cell adherence suggests that mycobionts do as well. Additionally, mycobionts are known to use a combination of class I hydrophobins and ECM for mycobiont-photobiont and also potentially mycobiont-bacterial cell adherence $[11,44,47]$. 
The initiation stage is also the point at which cell differentiation occurs and microcolonies form $[32,39,46]$. This stage is particularly important for multi-species biofilms since it is the first step towards niche determination within the cells. The differentiation and arrangement of niches allows for optimal usage of "microniches" that form within the biofilm, such as anaerobic zones. When a microbe fills a specific niche, it increases overall biofilm fitness $[32,71]$. How these microcolonies form and how cell differentiation occurs has been the topic of recent research, and although this is still poorly understood, the current consensus is that numerous factors trigger cell differentiation [71]. Various conditions that contribute to the formation of cell differentiation and microniches include abiotic factors, the organisms involved in the biofilm, and specific gene switches. For example, Vlamakis et al. [39] investigated the spatiotemporal shift of three types of differentiated cells in Bacillus subtilis biofilms, where they observed a shift in cell types. Observed cell types varied in abundance over time, with motile cells being the first type of cells (which formed the initial biofilm), then matrix cells becoming the majority of the second stage, and finally sporulating cells to allow for dispersal of the microbes. All three types of cells were observed at each time point but in different locations within the biofilm and in varying abundance. This evidence suggests that even within a mono-cultured biofilm, diversification of cell type is both present and essential to the overall fitness of the biofilm.

Quorum sensing molecules (QSM) or cell-signaling chemicals have also been linked to cell differentiation in both fungal and bacterial biofilms [31]. When the gene lasl, which encodes for the formation of acyl-homoserine lactones (acyl-HSLs), was deleted from Pseudomonas aeruginosa, it formed flat-nondifferentiated biofilms that were easily disrupted by a detergent such as SDS, but recovered after addition of external acyl-HSL [72]. QSMs are not specific to bacteria, as farnesol has been identified as a quorum sensing molecule produced by the fungal pathogen Candida albicans in its planktonic state [73]. However, exposure of $C$. albicans or its close relative C. dubliniensis, to $10 \times$ the normal amount of farnesol disrupts biofilm formation $[74,75]$. Candida albicans is unable to form biofilms in the presence of farnesol because it blocks the switch to hyphal growth [73-75], and the switch from white to opaque cells, which are both vital to the 
formation of biofilms during the initiation step [76]. Since increased farnesol inhibits the progression into the filamentous form, it in turn inhibits biofilm formation [74,75]. In most Ascomycete biofilm-forming fungi, hyphal growth is necessary for biofilm production [46,48,77]. This phenomenon is found mainly in Pezizomycotina, the fungal subdivision where the majority of lichen-forming fungi are phylogenetically derived $[1,78]$.

Lichen cell differentiation is very understudied, and there is little to no understanding of pre-thallus cell differentiation. Most studies in this area have focused more on the later aspects of cell differentiation. However, cell differentiation is vital to the initial formation of the lichen thallus (i.e., body), which is composed of 4 (or more) distinct zones: the upper cortex, the algal layer, the medullary thalline layer, and the lower cortex [42]. Separation into these layers and cell types allows for the algae to be exposed to light, for gas and water to exchange between layers, and reduced desiccation [42,44]. This degree of cell differentiation is believed to form after much of the initial growth, and therefore this stratification occurs during the aptly named stratified thallus/ stratification stage $[7,79]$. A recent publication by Roth et al. [80] have indicated that lichen cell differentiation occurs in a stem cell-like fashion, in which the outer cortical fungal cells differentiate by emerging from internal medullary hyphae "stem cells". Unlike C. albicans, mycobionts have been known to maintain their hyphal state even outside of the lichen symbiosis and only one mycobiont (Umbilicaria muhlenbergii) recently has been identified to have a yeast state outside of the symbiosis [81]. Notably, hyphal branching is more vital in lichen formation and biofilm-forming filamentous fungi $[80,82]$, while hyphal branching is not commonly observed in C. albicans biofilms [83]. Lichen cell differentiation is vital for structural differences, which are not obvious until later stages, understanding the factors that drive thallus stratification and cell differentiation in the mycobiont cells will greatly contribute to our knowledge of lichen development. As C. albicans uses QSM to block biofilm formation, one would hypothesize that a quorum sensing molecule in lichens- whether sourced from fungal, algal, or both partners- may also play a role in lichen cell differentiation. 


\subsection{Maturation/stratification stage}

The third stage of biofilm formation is the maturation stage. This stage is characterized by more pronounced cell differentiation or stratification, the formation of ECM, and the development of stress resistance mechanisms (Fig. 3). At this stage only physical removal can disrupt biofilm organization [84]. The combination of matrix formation, cell differentiation, and the subsequent development of specific structures provides biofilms with increased resilience relative to their planktonic form. In lichens, this stage is called the stratified thallus stage, where individual structural layers form to provide different functions, and subsequently this is the stage the lichen will remain in for many years $[7,79]$. ECM formation is one of the main features of the maturation stage of biofilms $[31,38,46]$. Similarly, the stratification of lichen thalli is also marked by the formation of "conglutinate zones", or the formation of the lichen matrix, by fungal (and likely photobiont) secretion of the mucilaginous matrix [7]. This matrix layer that forms around biofilms, and easily recognized in the lichen thallus, is important to the survival of both communities.

For biofilms and lichens alike, this stage is most important to the structural architecture that allows for optimal microbial interactions and survivability of all cells in the community. The initial parts of this stage are key to the shifting of cell types, which precedes structure formation. Although pili and flagella are integral to this shifting stage of many bacterial biofilms there are no known lichen-forming fungi capable of such coordinated movement in this way [27,31]. Like other filamentous fungi, lichen mycobionts employ polar growth and hyphal branching to interact with partner algae and to develop the thallus [80,82,85-87]. Fungal biofilms formed by C. albicans have similar structural changes since, they also rely on polar growth of their hyphae to create a biofilm [46].

Re-positioning of cells during this stage of lichen or biofilm development allows for tunnels to form, which are key to gas and liquid exchange. In biofilms, these structures are termed interstitial voids and are typically located at the base of the biofilm [27]. In lichens these structures are traditionally called pseudoparenchyma and are on the surface of the lichen [88]. Recent research suggests that they may be 
a result of hydrophobic layers formed between clumps of mycobiont and photobiont cells $[44,89]$. Nonetheless, both biofilms and lichens require mechanisms for gas and water exchange throughout the entire structure, to ensure availability of nutrients for all cells. The formation of upper and lower conglutinate cortices of lichens seemingly permits no way for air or water exchange to occur within the thallus. However, the matrix that coats the cells of the lichen contains an outer hydrophobic layer surrounding the matrix, allowing for gas exchange within an optimally wetted thallus $[11,44,47,89,90]$ (Fig. 5). When air moisture levels are low, the hydrophilic matrix shrinks like a dried dish sponge, allowing desiccation to occur. Desiccation shuts down cellular processes, which increases resistance to many stressors but also poses an issue by halting photosynthesis at peak UV exposure $[19,91,170]$. When air moisture is high, the hydrophobic layer surrounding the matrix subsequently reduces over wetting of the thallus and increases the timespan for photosynthesis, by allowing gas exchange to still occur as the hydrophilic matrix expands like a wetted dish sponge [44]. This process of passive water regulation is called poikilohydry, as it uses no active cellular processes to regulate water retention $[19,91,170]$. Although, at full hydration photobionts are still unable to perform photosynthesis [19]. The process is not a perfect solution, but without this hydrophobic layer the timespan for photosynthesis to occur would be much shorter (Fig. 5).

Mycobiont cell polarization facilitates arrangement of photobiont cells for optimal light exposure - arguably the most important trait to the success of the lichen symbiosis. Mycobiont hyphae will grow in such a way to shift the photobiont to the upper medullary thalline layer (surface layer) and position the photobiont cells so they will be exposed to sunlight $[85,89]$. Fungal positioning of the photobiont cells removes the responsibility of optimizing light exposure from the photobiont, and instead placing all the work on the fungal partner. Other fungal-photosynthetic organism interactions, such as mycorrhizal fungal symbioses, rely on the photosynthetic partner as the organism responsible for orienting towards the light. This is one argument that has been made for the symbiosis of lichens to be mutualistic instead of parasitic, because the mycobiont is providing a vital resource in the form of cell movement to the non-motile photobiont $[20,92]$. Without the proper structural organization to allow for gas 
and water exchange, and the correct positioning of the photobiont cells photosynthesis would not occur, compromising the lichen symbiosis. A similar phenomenon can be accounted for in all microbial biofilms as their specific structural organization - the formation of interstitial voids - is optimized for the air and water exchange required by each organism in the biofilm [27,38]. In some multi-species biofilms, anaerobic zones within the biofilm allow specific syntrophys to form between anaerobic organisms, such as anaerobic archaea and aerophilic bacteria [31]. Microniches that form within microbial biofilms via cell differentiation and community diversity accommodate specific interactions that may not have formed outside of the biofilm. The effect is an increase of the overall fitness of the microbial collective, which is hypothesized as one initiating factor driving these interactions towards mutualism [169]. This may be how lichen interactions originally formed, via aggregation within a biofilm, then co-evolving over millions of years to form the more permanently structured lichen thallus.

\subsection{Reproduction and dispersal stage}

The last stage in biofilm formation is the dispersal stage, which allows the biofilm to spread to new locations, and is characterized by sporulation, shedding of vegetative cells, or cellular detachment $[27,46]$ (Fig. 3). This stage resembles the end-stage growth of most microbes, but for some biofilm-forming microbes the ability to sporulate or disassociate requires they be in a biofilm. In both lichens and biofilms, dispersal may be non-sexual (vegetative spreading) or an asexual/sexual sporulation event. Vegetative spreading of biofilms may result from loss of a vital nutrient source, shearing caused by fluid movement, or by an autoinducer chemical signal [93-95]. Biofilm dispersal promotes survival, allowing the biofilm to persist elsewhere. Although this process occurs throughout biofilm-forming organisms, the environmental and chemical triggers can vary across species and conditions.

Compared to biofilms, lichens' propensity for and mechanism of dispersal is comparatively much less understood. It has been noted that lichens are sometimes incapable of dispersing very far [96], however, the production of various sporulating and vegetative structures is very well characterized in lichens, suggesting dispersal is vital in their development $[7,51,65,90]$. Spore-formation varies widely between 
lichen taxa, but one common theme is that no lichen separation experiments have observed sporulation events of the mycobiont when it is grown axenically and sporulation has been observed to be restored by re-synthesis [97-100]. Overall, mating in fungal organisms is very complex and well-studied in only a few model organisms, particularly yeasts such as Saccharomyces cerevisiae. For example, in C. albicans the genes required for biofilm formation (ex: the switch from white to opaque cells, and adhesin proteins: Eap1, Pga10, Hwp1, Hwp2, \& Rbt1) are also important for mating $[46,101]$. The link between mating and biofilm-formation in C. albicans is novel to fungal mating and it will be important to elucidate mating across other biofilm forming fungi and lichens. Notably, the presence of canonical mating components in sequenced lichen genomes suggest similar mechanisms of $C$. albicans mating and those employed through the lichen symbiosis [102].

\subsection{Interactions}

In multi-species biofilms, interactions between microbes tend to be symbiotic or syntrophic in nature, such that one microbe produces a product that another uses as a substrate [31]. Biofilms promote persistent interactions between microorganisms and, in an economic sense, allow for nutrient niche economy such that the organisms always are within "flagella's reach" of what they collectively need. This phenomenon can be observed in anaerobic digestion vessels during wastewater treatment, which contain fermentative bacteria, acetogenic bacteria, and methanogens. Fermentative bacteria produce alcohols, which are used by acetogenic bacteria as a carbon source, who then produce acetate as a byproduct that is used by the anaerobic Methanogens as a carbon source - the final step in the carbon cycle [103]. This exemplifies the typical biotic interactions that occur and are vital to a well-developed biofilm [31,32,104].

Lichens are a prime example of microbial syntrophy, where the mycobiont creates the "home" for the photobiont protecting it from the external stressors and orienting the photobiont for optimal UV exposure, while the photobiont in turn produces carbohydrates and occasionally reduced nitrogen (from cyanobacteria) [7]. Bacterial involvement in lichens is still poorly understood but likely is involved with nitrogen production in non-cyanolichens by utilizing other 
nitrogen-fixing bacteria from the order Rhizobiales to obtain reduced nitrogen, since they are the most abundant order found on lichens thus far $[12,14]$. Microbial syntrophy allows biofilms and lichens to rely less on external abiotic acquisition of nutrients, in favor of becoming self-sustainable and more persistent. Lichens have co-opted this strategy to their evolutionary advantage. By leveraging the combination of photosynthetic partners and flexible carbohydrate consumers in fungi, lichens have practically everything they need from biotic origins.

Recognition between the surrounding microbial species is also crucial to both biofilm and lichen formation. Quorum sensing molecules such as acyl-HSLs are one mechanism that microbial biofilms use to determine the identity of neighboring species and facilitate formation of multispecies biofilms [105]. These compounds are species- and even strain-specific, which allows organisms to identify self, "friend", and "foe" - allowing for precise interactions between organisms within the biofilm [31]. These QSM are utilized in almost every stage of biofilm formation but are especially important in the development of interactions between microbes in the biofilm. One prime example of interactions between biofilm-forming microbes and their QSM is the interactions of $C$. albicans with $P$. aeruginosa and Streptococcus gordonii $[106,107]$. Candida albicans is known for producing the QSM farnesol, which has been studied for its multiple roles in the C. albicans lifestyle [73]. For instance, when C. albicans and P. aeruginosa are near one another, their respective QSM inhibit each other's growth. Farnesol will prevent $P$. aeruginosa from producing the toxic phenazine pyocyanin, which in turn reduces its virulence [108]. Simultaneously, P. aeruginosa produces its QSM called 3-oxo-C12homoserine lactone, which represses filamentous growth in C. albicans reducing its biofilm forming abilities [106]. Alternatively, S. gordonii promotes the production of $C$. albicans hyphae and therefore biofilm development in the oral cavity [109]. This phenomenon is believed to be regulated via secretion of Autoinducer 2 by S. gordonii indicating a different microbial interaction caused by similar chemical interactions [109].

No QSM or other known interactive secondary metabolites have been identified in lichens so far, but it is likely that they utilize chemical signaling due to their well noted abundance of secondary metabolites. Even amongst eukaryotes QSMs are poorly understood. However, 
recent studies show that the alga Chlorella sorokiniana produces the auxin family of phytohormones [110]. Because this alga belongs to the same class as most lichen photobionts (Trebouxiophyceae), this observation suggests a role for phytohormones in mediating mycobiont-photobiont interactions. Additionally, multiple studies implicate lichen-made secondary metabolites (e.g., usnic acid and evernic acid) in the prevention of unwanted bacterial growth in Streptococcus spp. and $P$. aeruginosa biofilms respectively $[111,112]$. These biofilmreducing secondary metabolites resemble the role of farnesol in their capacity to disrupt bacterial biofilms. Since farnesol is a QSM capable of reducing biofilm formation in $P$. aeruginosa and other bacteria, it is not surprising that usnic acid and evernic acid are also capable of dispersing biofilms, and as such they may be later termed lichen QSM or, at the very least, communication molecules [111,112].

During lichen partner recognition, lectin-mediated interactions between mycobionts and photobionts trigger either a compatibility or incompatibility reaction by the photobiont [113]. Lectins, which are carbohydrate-binding proteins, are used frequently by pathogenic fungi, bacteria, and viruses to identify their hosts [114]. Certain lichens will only form between specific species of a mycobiont and a photobiont, while other partner interactions are much less specific, as some mycobionts can utilize more than one type of photobiont $[24,115]$. However, lectin recognition only occurs after the mycobiont has made physical contact with the potential photobiont. Other studies have shown that there may be some form of unknown chemical signaling occurring between the symbionts before physical contact is made [64]. These chemical signals are photobiont-specific, in that when multiple photobiont supernatants were exposed to a single mycobiont each of the supernatants caused different growth forms of the mycobiont. Exposure to the correct photobiont's supernatant resulted in increased ECM production, increased hyphal growth, and increased hyphal branching, all important aspects of initial thallus development [64]. Although this is only one example of pre-contact interactions between lichen symbionts, it is still strong evidence for the importance of chemical interactions in lichen development, which are analogous in biofilm development.

Insight into that unknown mechanism can be gained from interactions between plants and mycorrhizal fungi. Though mycorrhizal 
fungi-plant interactions are not generally thought of as biofilms, the manner in which ectomycorrhizal (or "sheathing") fungi attach and surround the roots of plants by use of an extracellular matrix strongly resembles biofilm formation $[116,117]$. For mycorrhizal fungi to identify their plant host, the plant and mycorrhizal fungi secrete specific phytohormones, similar to that of QSM in fungal and bacterial biofilms [118]. Plant phytohormones secreted by mycorrhizal fungi are typically auxins, and plants in turn secrete strigolactones that the fungus may identify. After their chemical signals are exchanged, both organisms exhibit lateral growth towards the source of the chemical signal to locate their symbiont [118-121].

Microbial interactions within biofilms and lichens are very complex in nature and inherently difficult to study. We still are lacking most information regarding how microbes interact within consortia. These few specific interactions represent only a fraction of what actually facilitates or regulates biofilms and lichens in their natural environments. Even amongst lichenologists, the nature of the lichen relationship is contested; it may be true symbiosis, or controlled parasitism [40,122]. To elucidate the complex relationships between microorganisms, researchers are moving towards systems-biology approaches to simultaneously probe the multi-species transcriptome [35] and characterize their phylogenetic diversity in microbial communities $[3,123]$. Subsequently, biologically important mechanisms can be deduced from those vast libraries of knowledge and utilized to perform specific experiments based on the information from the systemslevel approaches. In order for microbial ecology and interactions to be resolved we must expand the use of these and other approaches.

\section{Extracellular matrix}

\section{1. Matrix details from biofilms and lichens}

One of the most important features of a biofilm is their extracellular polymeric substance or the extracellular matrix $[28,78]$. In biofilms, this matrix contains polysaccharides, proteins, nucleic acids, lipids, and secondary metabolites - all of which vary in composition due to the overall species diversity, abundance, and specific chemical interactions 
[124]. The ECM is seen in the initial formation of the biofilm but is not fully formed until the biofilm reaches maturity. Not only is the ECM essential for maintenance of structural integrity, but it also plays a key role in resistance to abiotic stresses such as desiccation, as well as external stress caused by antimicrobial drugs or the human immune system [124]. Although it has been established that inner layers of the ECM contain mostly hydrophilic polysaccharides that mediate desiccation resistance [124], they also possess outer hydrophobic layers to allow for hydrophobic substrate binding and prevent water loss from the hydrated inner structures of the ECM $[55,61,63,68,125]$ (Fig. 5). Additionally, the hydrophobicity of the substance the biofilm is attached to has been shown to alter the hydrophobicity of the outer matrix layer [126]. This allows biofilms to adapt to surfaces as they attach, allowing for both hydrophobic and hydrophilic attachments.

Our understanding of the ECM in lichens is largely confined to that which surrounds the cells. Additionally, the variable nomenclature for the lichen ECM, which ranges from regular "extracellular polymeric substance", to the aptly named "gelatinous matrix", and the structural term "conglutinate" $[7,40,44]$ has likely hindered attempts to understand its properties. However, with the help of two recent publications $([89,127]$ series) and information on the lichen ECM scattered throughout the literature, we can construct a loose understanding of the structural composition and biological role of the ECM, that bears similarity to biofilm matrices. We know for certain that the lichen matrix contains a variety of polysaccharides [127], crystalline secondary metabolites such as usnic acid, and proteins; and that parts of the lichen thallus' ECM are surrounded in a hydrophobic outer layer $[11,41,44,47,58]$. This composition is therefore extremely similar to the extracellular matrix of biofilms $[78,117]$.

Another feature of the biofilm matrix is the presence of external DNA, which promotes horizontal gene transfer between the biofilm members $[124,128,167,167,168]$. Although the presence of external DNA in the lichen ECM remains untested, multiple horizontal gene transfer events have been observed within various lichens [102,129-131]. In particular, the lichen Xanthoria parietina's genome harbors three genes that were likely transferred from the mycobiont to the photobiont several millions of years ago [129]. Phylogenetic analysis suggests that this transfer preceded the origins of the lichen 
symbiosis, which implies that fungi and algae have a long history of intimate interactions $[37,129]$. Accordingly, it is tempting to speculate that such "proto-lichens" might have existed within a protective biofilm-like matrix that facilitated interactions and enabled gene transfer. Currently, the matrix-containing components of lichens have been isolated to the upper and lower cortices which are called "conglutinate zones" [42]. The lower cortex allows for attachment to the substrate, and the upper cortex controls the transfer of liquids and gases and provides environmental protection. The isolation of the lichen matrix to these two zones is not confirmed, and it is likely that a variety of matrix layers coat all of the lichen cells based on the images captured by Honegger \& Haisch [44] and Roth et al. [80]. Biofilms are completely coated by their ECM, which implies that lichens would presumably also have a complete coating of matrix material, instead of ECM isolated to specific layers. The similarities between lichen and biofilm matrices detailed above suggest lichens do indeed have an extracellular matrix analogous to biofilms, which is vital to the persistence of these communities within the extreme environments they typically inhabit. The successful lifestyles of lichens and biofilms are undoubtedly dependent upon the ability of the matrix to contain water, mediate environmental resistance, and promote cell-cell adhesion.

\subsection{Closer look at the matrices of the filamentous fungus Aspergillus} fumigatus and the lichen Cetraria islandica

Studies have focused on the filamentous fungus Aspergillus fumigatus, a human pathogen, regarding its biofilm-forming capabilities $[68,132]$. These studies have concluded that $A$. fumigatus is indeed capable of forming an extracellular matrix and therefore is also capable of forming a biofilm. The matrix of $A$. fumigatus contains polysaccharides (particularly galactomannan and $\alpha-1,3$-glucans), monosaccharides and polyols, secondary metabolites (like melanin), as well as proteins [68]. One of the most intriguing findings from Beauvais et al. [68] was the location of $\alpha-1,3$-glucans within the extracellular matrix. Via immunogold labeling, they identified $\alpha-1,3$-glucans in the matrix and right on the outer edge of the cell wall, but not within the cell wall. Similarly, Honegger and Haisch [44] observed the $\beta$-1,3-glucan lichenin in the lichen Cetraria islandica in the same locations as $A$. 
fumigatus. In both studies, polysaccharides were only located in the extracellular matrix and not in the cell wall, where fungal glucans are also known to be located. In addition, both authors commented on the location of hydrophobic versus hydrophilic substances and proteins in relation to the cell wall and matrix. In A. fumigatus, hydrophobin proteins were said to be located within the matrix but with no further details on localization mentioned. Whereas, in $C$. islandica it was noted that the matrix itself was hydrophilic with a thin hydrophobic proteinaceous outer layer $[44,68]$ (Fig. 4). The thin hydrophobic layer is thought to allow photosynthesis to continue when the

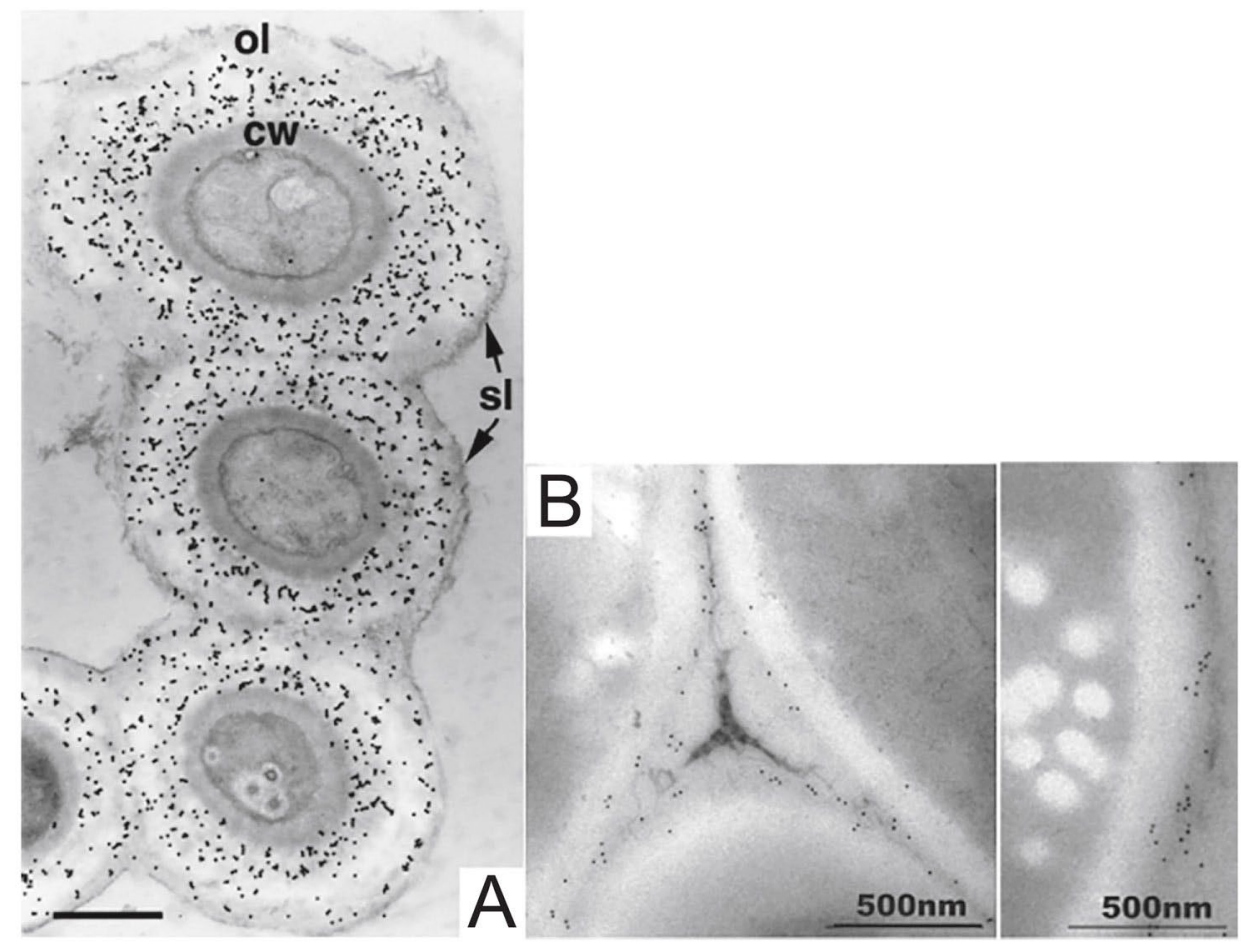

Fig. 4. Transmission Electron Microscopy images of immunogold labeling experiments locating 1,3-Glucans in the lichen $C$. islandica (A) and A. fumigatus (B). (A): Immunogold labeling of $\beta-1,3-$ Glucans in the lichen $C$. islandica [44]. Lichenin is presumed to be the glucan that is labeled, which is shown to be mainly accumulated in the outer layer (ol), which is indicated to be the extracellular matrix of the lichen; bar = $1 \mu \mathrm{m} ; \mathrm{cw}=$ mycobiont Cell wall; $\mathrm{sl}=$ surface layer. (B): Immunogold labeling of $\alpha-1,3$-Glucans in the fungus $A$. fumigatus [68]. The $\alpha-1,3$-Glucans are also observed to be accumulated in the extracellular matrix of $A$. fumigatus biofilms as well. Indicating that both lichens and fungal biofilms create extracellular matrixes that contain extracellular polysaccharides. 

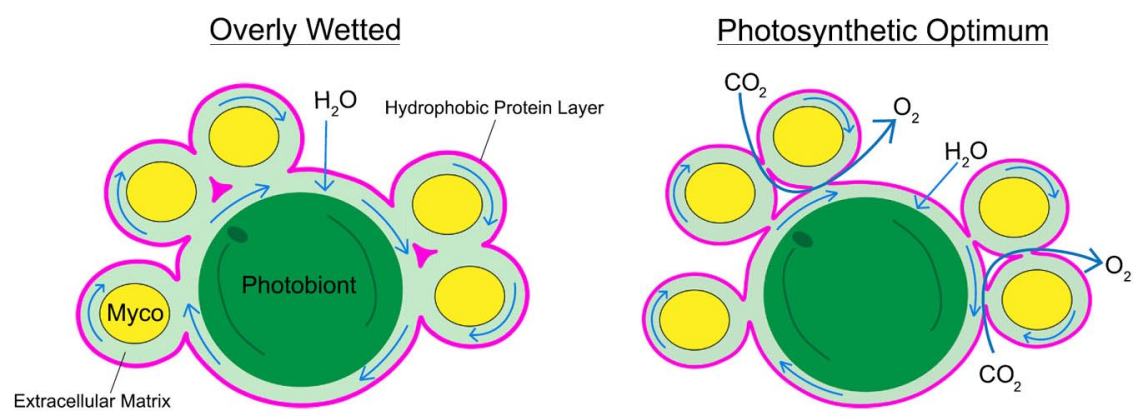

Fully Desiccated

Fig. 5. Illustration of the lichen extracellular matrix in relation to the mycobiont and photobiont cell walls, and its effect on lichens' poikilohydric lifestyle. The matrix is located beyond the mycobiont's cell wall, it is hydrophilic due to its excess in hygroscopic glucans allowing for water accumulation and exchange. Additionally, there is a thin hydrophobic proteinaceous coat that surrounds the extracellular matrix and photobiont cells, indicated here with a thick pink line. This is presumed to prevent over wetting of the lichen thallus, to allow for important gas exchange to occur that is vital to photosynthesis, and also to aid in the water retention of the matrix acting like a plant's cuticle.

lichen is wetted and the extracellular matrix is expanded [44]. Without the hydrophobic layer the photobiont would be incapable of gas exchange, and therefore photosynthesis (Fig. 5). If there are indeed differences between the matrices, they are likely influenced by the differences in life-history of these two different entities. Lichens exist in xeric conditions with quickly fluctuating periods of wetting and drying, whereas A. fumigatus is found in the misty environment of the lungs. In both cases, the presence of the glucans in their extracellular matrix is likely to facilitate the agglutination of the fungal cells to form a lichen thallus or a biofilm.

\section{Resistances to environmental stressors}

\subsection{Environmental stress resistance of biofilms and lichens}

An evolutionarily selected for trait of the biofilm lifestyle is an increase in resistance to a variety of stressors [133]. This key feature is frequently used to test whether an organism is biofilm-forming, and whether knocking-out a key gene affects biofilm formation in certain species $[134,135]$. All biofilms that have been studied so far are 
noted to have multiple environmental resistances that include antimicrobial drug resistance, ultraviolet (UV) radiation, metal toxicity, osmotic shock resistance, desiccation resistance, and $\mathrm{pH}$ shift resistance $[31,136]$. Lichens share this multi-resistance phenotype with biofilms, and numerous studies have been performed to understand lichen resistances to various abiotic stresses. Most notably, lichens are known to be resistant to UV radiation, metal ion toxicity, desiccation, and extreme temperatures simultaneously [137]. As an example of this extreme multi-resistance, the survivability of the lichen Xanthoria elegans was tested in the exposed vacuum of space for 1.5 years $[138,139]$. These experiments revealed that $X$. elegans survives the vacuum of space by exploiting its poikilohydric lifestyle to shut down metabolism while in extreme xeric conditions and restarting metabolism when humidity levels were optimal upon their return. Although a complete understanding of the variety of resistance factors is far from being understood, it is clear that one of the main contributors to abiotic resistance is their ECM coating $[140,141]$. How important the matrix is, and other factors that may be involved in resistance mechanisms varies between environmental stressors, so taking a closer look at each external factor, the cause of resistances, and the shared themes between lichens and biofilms will be explored here.

\subsection{Metal toxicity resistance}

Lichens have long been recognized as biomonitors for their ability to absorb multiple types of pollutants such as heavy metals and atmospheric pollutants like sulfuric and nitrous oxides (SOX and NOX) [142144]. Consequently, lichens have been used to identify common air pollutants in some cities as lichen distribution patterns and extracted compounds may serve as an indicator of air quality [143]. Unlike metal resistance mechanisms of some bacteria, the ability of lichens to resist metals is not a result of changing the chemical state of the metal. Instead, lichens typically sequester the metal ions into their cellular structures $[43,145,146]$. Metal ions are known to adhere to the chitinous cell wall of most fungi, but especially lichen forming fungi. Lichens are even recognized for the coloration that results from the sequestering of metals onto their thallus [43]. This makes lichens and other fungi prime candidates for bioremediation since they absorb metal 
ions from their surroundings instead of merely changing the state of the metal ions. Alternative forms of metal resistance in lichens include binding of metal to intracellular spaces of hyphal filaments (likely the matrix), binding of metals to metallothioneins (small cysteine proteins), and complexing of metal ions to organic acids produced by lichens such as oxalate and evernic acid [142]. Each of these methods allows lichens to be hyperresistant to harmful metals.

Biofilms are also recognized for the ability to sequester metal ions $[147,148]$. Metal ions typically adhere to the ECM of biofilms, instead of the cells themselves, which protects the microbes from metal toxicity [149]. Additional methods of metal resistance in biofilms include: siderophore production, persister cells, metal metabolic processes (found in specific bacteria), and overall reduced metabolic processing [150]. Multi-metal resistance capabilities of biofilms have also led researchers to investigate their bioremediation capabilities, even utilizing biofilms in water purification techniques [151]. The capacity for both lichens and biofilms to resist metal toxicity shows their capability to survive in more hash environments than most planktonic microbes. Through their microbial community they are more resistant together than they are as individual cells.

\subsection{UV \& desiccation resistance}

Resistance to UV radiation and desiccation are crucial for sun-exposed microbes. For example, living on a rock or tree leads to intense UV along with dramatic daily and seasonal shifts in water activity. The properties of biofilms and lichens suggest that they might play a key role in mitigating the impacts of these stresses. Ultraviolet light radiation is recognized for its ability to cause DNA damage [152] such as misincorporation of nucleotides during transcription and translation, direct oxidative damage, or nucleotide modification such as thymine-thymine dimers [153]. While low levels of UV radiation are easily repaired by normal DNA repair mechanisms, surface dwelling microorganisms are subjected to higher levels of UV [153]. Alternative mechanisms of UV radiation resistance rely on the initial blocking of UV exposure, typically via secondary metabolites such as carotenoids, melanin, and other UV-absorbing compounds [152]. 
Lichens are well-known for their UV resistance capabilities. They are some of the only organisms that can grow in extreme UV conditions such as the arctic poles, on mountains, and desert conditions [154]. Furthermore, when lichens are exposed to peak UV radiation at midday, they are also typically in a desiccated state which halts all cellular processes to prevent death by desiccation, a process attributed to their poikilohydric lifestyle [91]. This means lichens are incapable of performing DNA-repair while desiccated and exposed to high amounts of UV radiation, therefore, they have evolved alternative UV resistance measures. Lichens utilize their capability to produce extensive amounts and types of secondary metabolites as their main source of defense against UV radiation. Numerous compounds produced by lichens that are resistant to UV radiation include melanin, carotenoids, usnic acid, parietin, polyketides, and other secondary metabolites which are all mycobiont-sourced, whereas mycosporin is one of the only UV resistant compounds that is only produced by cyanobacteria in cyanolichens [155]. These compounds are typically bound to the fungal cell walls of the mycobiont, particularly in the upper cortex and medullary layers, where exposure to UV radiation is the highest [156]. Whether the mycobiont partner can create an array of UV protectant compounds when grown in isolation has not yet been studied. However, it seems likely that the UV protective nature of secondary compounds produced by the mycobiont would have been selective for the photobiont to form a lichen symbiosis.

Biofilm resistance to UV radiation is mainly dependent on the capability of the extracellular matrix to block UV from penetrating far through the biofilm. Researchers previously determined that $P$. aeruginosa extracellular matrices have a very strong capacity to block UV exposure, only allowing $13 \%$ UV-C, 31\% UV-B, and 33\% of UV-A to penetrate the matrix, with UV-C being the most harmful [157]. Most microbial biofilms surveyed to date rely primarily on DNA repair mechanisms in addition to their matrix to resist UV-induced damage [158]. To date, the mechanism underlying UV absorptive properties of the ECM remain unknown, but the presence of copious polysaccharides is thought to play a role [157]. In addition, it would not be surprising to find secondary metabolites within the biofilm matrix that contribute to UV resistance like that in lichens. Additionally, one of the most successful ways for a microbial biofilm to resist UV damage is to 
incorporate already extremely UV resistant microbes, into their matrix, as observed in biofilms that formed on the Chernobyl nuclear reactor cooling towers [159]. These biofilms contain melanized fungi, as well as bacterial and fungal species that are known to be radiation resistant, and even non-UV resistant microbes such as S. cerevisiae [159]. This observation suggests that microbes that possess only "standard" UV resistance mechanisms can survive high levels of UV radiation by co-inhabiting in biofilms with UV resistant organisms.

Desiccation resistance in biofilms and lichens largely stem from their ECM. In both communities the ability to resist desiccation is attributed to their thick extracellular matrix, which can hold water within their excess of hygroscopic polysaccharides $[160,161]$. In biofilms formed by $P$. aeruginosa and other Pseudomonads, it has been determined that the polysaccharide alginate located in the extracellular matrix is the main contributor of desiccation resistance [162]. Within lichens, many polysaccharides have been identified all of which are noted to have hygroscopic tendencies that aid in desiccation resistance $[44,127]$. However, additional desiccation resistance in lichens can be attributed to the outer layer of hydrophobic proteins on the outside of the extracellular matrix, possibly acting like the cuticle of plant leaves $[44,58]$. This allows the water to be maintained within the matrix reducing evaporation through the matrix. This additional layer contributes a higher degree of desiccation resistance in lichens which is vital to the specific niche they hold amongst the surface-attached microbes.

\section{Concluding remarks}

An abundance of similarities between lichens and microbial biofilms allow us to make many connections between the two consortia. The stages of their development both follow a regimented progression with surface adherence as the first stage, cell morphological transition in the second stage, stratification of cell types in the third stage, and dispersal of cells as the final stage. Both position their cells in ways that allow for proper gas and water exchange, either through interstitial voids or the medullary thalline layer. Similar protein types are used for cell-surface adherence and cell-cell adherence. Quorum 
sensing molecules and lectins provide biofilms and lichen-related organisms the ability to identify the microbes around them, allowing for specific positive and negative interactions such as syntrophy and competition. Additionally, they both contain an extracellular matrix which is essential to their cohesion and stress resistance to various environmental factors. Understanding of these attributes has been arguably more researched in biofilm literature. Thus, providing lichenologists a potential starting point when identifying cellular processes for these features.

With this starting point, further identification of specialized properties of lichens can be elucidated. Are quorum sensing molecules important in mycobiont-photobiont interactions? What triggers mycobiont cells undergo cell differentiation to begin stratification of the thallus? How extensive is the extracellular matrix in lichens, and what does it specifically contain? Finally, one of the most sought-after questions of lichenologists, how did lichens come to exist and evolve? Similarities between lichens and biofilms listed here in our review point to the concept that lichens likely started out as a biofilm, then over millions of years of co-evolution between the partners they formed the unique structure that we know of as the lichen. These questions and many others can be extrapolated from focusing on the cellular processes within biofilms and determining how they may overlap with lichens.

\section{$\diamond \diamond \diamond$}

\section{CRediT authorship contribution statement}

Erin C. Carr: Conceptualization, Writing - original draft, Writing - review \& editing, Visualization.

Steven D. Harris: Funding acquisition, Project administration, Supervision, Writing - review \& editing.

Joshua R. Herr: Visualization, Writing - review \& editing.

Wayne R. Riekhof: Funding acquisition, Project administration, Resources, Supervision, Validation, Writing - review \& editing.

Declaration of competing interest The authors certify that they have NO affiliations with or involvement in any organization or entity with any financial interest (such as honoraria; educational grants; participation in speakers' bureaus; membership, employment, consultancies, stock ownership, or other equity interest; and expert testimony or patent-licensing arrangements), or non-financial interest (such as 
personal or professional relationships, affiliations, knowledge or beliefs) in the subject matter or materials discussed in this paper.

Acknowledgments Funding for this work was provided by National Aeronautics Space Administration (NASA) (grant number 80NSSC17K0737). We would like to thank Ursula Goodenough and Toby Spribille for helpful communications, edits early on, and for providing unpublished manuscripts related to this work, and Kristi Montooth and Etsuko Moriyama for their useful insight into early versions of this manuscript. Additional thanks to Sean Carr for idea-bouncing as well as intellectual and emotional support.

\section{References}

[1] A. Gargas, P.T. DePriest, M. Grube, A. Tehler, Multiple origins of lichen symbioses in fungi suggested by SSU rDNA phylogeny, Science 268 (5216) (1995) 1492-1495.

[2] F. Lutzoni, J. Miadlikowska, Lichens, Curr. Biol. 19 (13) (2009) R502-R503.

[3] D. Hibbett, K. Abarenkov, U. Kooljalg, M. "Opik, B. Chai, J. Cole, J.R. Herr, Sequence-based classification and identification of Fungi, Mycologia 108 (6) (2016) 1049-1068.

[4] C.C. Plitt, A short history of lichenology, Bryologist 22 (6) (1919) 77-xii.

[5] D. Andes, J. Nett, P. Oschel, R. Albrecht, K. Marchillo, A. Pitula, Development and characterization of an in vivo central venous catheter Candida albicans biofilm model, Infect. Immun. 72 (10) (2004) 6023-6031.

[6] C.J. Nobile, H.A. Schneider, J.E. Nett, D.C. Sheppard, S.G. Filler, D.R. Andes, A. P. Mitchell, Complementary adhesin function in C. albicans biofilm formation, Curr. Biol. 18 (14) (2008) 1017-1024.

[7] R. Honegger, Developmental biology of lichens, New Phytol. 125 (4) (1993) 659-677.

[8] V. Tuovinen, S. Ekman, G. Thor, D. Vanderpool, T. Spribille, H. Johannesson, Two Basidiomycete fungi in the cortex of wolf lichens, Curr. Biol. 29 (3) (2019) 476-483.

[9] R. Honegger, Simon Schwendener (1829-1919) and the dual hypothesis of lichens, Bryologist 103 (2) (2000) 307-313.

[10] M. Cardinale, J. Vieira de Castro Jr., H. Müller, G. Berg, M. Grube, In situ analysis of the bacterial community associated with the reindeer lichen Cladonia arbuscula reveals predominance of Alphaproteobacteria, FEMS Microbiol. Ecol. 66 (1) (2008) 63-71.

[11] U. Goodenough, R. Roth, Lichen 5: medullary and bacterial biofilms, Algal Res. (2020). In this issue.

[12] M. Grube, G. Berg, Microbial consortia of bacteria and fungi with focus on the lichen symbiosis, Fungal Biol. Rev. 23 (3) (2009) 72-85. 
[13] M. Grube, T. Cernava, J. Soh, S. Fuchs, I. Aschenbrenner, C. Lassek, G. Berg, Exploring functional contexts of symbiotic sustain within lichen-associated bacteria by comparative omics, ISME J. 9 (2) (2015) 412.

[14] B.P. Hodkinson, F. Lutzoni, A microbiotic survey of lichen-associated bacteria reveals a new lineage from the Rhizobiales, Symbiosis 49 (3) (2009) 163-180.

[15] R.A. Armstrong, T. Bradwell, Growth of foliose lichens: a review, Symbiosis 53 (1) (2011) 1-16.

[16] M.E. Hale Jr., Studies on lichen growth rate and succession, Bull. Torrey Bot. Club. (1959) 126-129.

[17] M. Webster, D.H. Brown, Preliminary observations on the growth of transplanted Peltigera canina under semi-natural conditions, Lichenologist 29 (1) (1997) 91-96.

[18] A. Seminara, J. Fritz, M.P. Brenner, A. Pringle, A universal growth limit for circular lichens, J. R. Soc. Interface 15 (143) (2018) 20180063.

[19] O.L. Lange, J.D. Tenhunen, Moisture content and CO 2 exchange of lichens. II. Depression of net photosynthesis in Ramalina maciformis at high water content is caused by increased thallus carbon dioxide diffusion resistance, Oecologia 51 (3) (1981) 426-429.

[20] R. Honegger, Functional aspects of the lichen symbiosis, Annu. Rev. Plant Biol. 42 (1) (1991) 553-578.

[21] T. Spribille, V. Tuovinen, P. Resl, D. Vanderpool, H. Wolinski, M.C. Aime, H. Mayrhofer, Basidiomycete yeasts in the cortex of ascomycete macrolichens, Science 353 (6298) (2016) 488-492.

[22] Juliane Blaha, Elisabeth Baloch, Martin Grube, High photobiont diversity associated with the euryoecious lichen-forming ascomycete Lecanora rupicola (Lecanoraceae, Ascomycota), Biol. J. Linn. Soc. 88 (2) (2006) 283-293.

[23] M.D. Piercey-Normore, The lichen-forming ascomycete Evernia mesomorpha associates with multiple genotypes of Trebouxia jamesii, New Phytol. 169 (2) (2006) 331-344.

[24] M.D. Piercey-Normore, P.T. DePriest, Algal switching among lichen symbioses, Am. J. Bot. 88 (8) (2001) 1490-1498.

[25] M. Galun, P. Bubrick, Physiological Interactions Between the Partners of the Lichen Symbiosis, in: In Cellular interactions (Pp. 362-401), Springer, Berlin, Heidelberg, 1984.

[26] F.L. Henskens, T.A. Green, A. Wilkins, Cyanolichens can have both cyanobacteria and green algae in a common layer as major contributors to photosynthesis, Ann. Bot. 110 (3) (2012) 555-563.

[27] R.M. Donlan, Biofilms: microbial life on surfaces, Emerg. Infect. Dis. 8 (9) (2002) 881.

[28] S.S. Branda, Å. Vik, L. Friedman, R. Kolter, Biofilms: the matrix revisited, Trends Microbiol. 13 (1) (2005) 20-26.

[29] L. Friedman, R. Kolter, Genes involved in matrix formation in Pseudomonas aeruginosa PA14 biofilms, Mol. Microbiol. 51 (3) (2004) 675-690. 
[30] C.H. Kowalski, J.D. Kerkaert, K.W. Liu, M.C. Bond, R. Hartmann, C.D. Nadell, R. A. Cramer, Fungal biofilm morphology impacts hypoxia fitness and disease progression, Nature microbiology 4 (12) (2019) 2430-2441.

[31] M.E. Davey, G.A. O'Toole, Microbial biofilms: from ecology to molecular genetics, Microbiol. Mol. Biol. Rev. 64 (4) (2000) 847-867.

[32] P. Watnick, R. Kolter, Biofilm, city of microbes, J. Bacteriol. 182 (10) (2000) 2675-2679.

[33] S. Junttila, S. Rudd, Characterization of a transcriptome from a non-model organism, Cladonia rangiferina, the grey reindeer lichen, using highthroughput next generation sequencing and EST sequence data, BMC Genomics 13 (1) (2012) 575.

[34] M. Kono, Y. Kon, Y. Ohmura, Y. Satta, Y. Terai, In vitro resynthesis of lichenization reveals the genetic background of symbiosis-specific fungalalgal interaction in Usnea hakonensis, BMC Genomics 21 (671) (2020).

[35] C.R. Kuske, C.N. Hesse, J.F. Challacombe, D. Cullen, J.R. Herr, R.C. Mueller, A. Tsang, R. Vilgalys, Prospects and challenges for fungal metatranscriptomics of complex communities, Fungal Ecol. 14 (2015) 133-137.

[36] Y.Y. Wang, B. Liu, X.Y. Zhang, Q.M. Zhou, T. Zhang, H. Li, L. Wang, Genome characteristics reveal the impact of lichenization on lichen-forming fungus Endocarpon pusillum Hedwig (Verrucariales, Ascomycota), BMC Genomics 15 (1) (2014) 34.

[37] F. Lutzoni, M.D. Nowak, M.E. Alfaro, V. Reeb, J. Miadlikowska, M. Krug, K. Hilu, Contemporaneous radiations of fungi and plants linked to symbiosis, Nature Communications 9 (1) (2018) 1-11.

[38] D. L'opez, H. Vlamakis, R. Kolter, Biofilms, Cold Spring Harb. Perspect. Biol. 2 (7) (2010) a000398.

[39] H. Vlamakis, C. Aguilar, R. Losick, R. Kolter, Control of cell fate by the formation of an architecturally complex bacterial community, Genes Dev. 22 (7) (2008) 945-953.

[40] V. Ahmadjian, J.B. Jacobs, Relationship between fungus and alga in the lichen Cladonia cristatella Tuck, Nature 289 (5794) (1981) 169.

[41] R. Honegger, Cytological aspects of the triple symbiosis in Peltigera aphthosa, J. Hattori Bot. Lab. 52 (1982) 379-391.

[42] R. Honegger, Lichens: mycobiont-photobiont relationships, in: Algae and Symbioses, 1992, pp. 255-275.

[43] R. Honegger, Lichen-forming Fungi and Their Photobionts, in: In Plant relationships (Pp. 307-333), Springer, Berlin, Heidelberg, 2009.

[44] R. Honegger, A. Haisch, Immunocytochemical location of the $(1 \rightarrow 3)(1 \rightarrow$ 4)- $\beta$-glucan lichenin in the lichen-forming ascomycete Cetraria islandica (Icelandic moss), New Phytol. 150 (3) (2001) 739-746.

[45] J.B. Jacobs, V. Ahmadjian, The ultrastructure of lichens. I. A general survey, J. Phycol. 5 (3) (1969) 227-240.

[46] J.S. Finkel, A.P. Mitchell, Genetic control of Candida albicans biofilm development, Nat. Rev. Microbiol. 9 (2) (2011) 109. 
[47] U. Goodenough, R. Roth, Lichen 2: constituents, Algal Res. (2020). In this issue.

[48] J.R. Blankenship, A.P. Mitchell, How to build a biofilm: a fungal perspective, Curr. Opin. Microbiol. 9 (6) (2006) 588-594.

[49] A. Krasowska, K. Sigler, How microorganisms use hydrophobicity and what does this mean for human needs? Front. Cell. Infect. Microbiol. 4 (2014) 112.

[50] P.N. Lipke, What we do not know about fungal cell adhesion molecules, J. Fungi 4 (2) (2018) 59.

[51] W.B. Sanders, R. Lücking, Reproductive strategies, relichenization and thallus development observed in situ in leaf-dwelling lichen communities, New Phytol. 155 (3) (2002) 425-435.

[52] J. Dynesen, J. Nielsen, Surface hydrophobicity of Aspergillus nidulans conidiospores and its role in pellet formation, Biotechnol. Prog. 19 (3) (2003) 1049-1052.

[53] H. Girardin, S. Paris, J. Rault, M.N. Bellon-Fontaine, J.P. Latgé, The role of the rodlet structure on the physicochemical properties of Aspergillus conidia, Lett. Appl. Microbiol. 29 (6) (1999) 364-369.

[54] B.E. Priegnitz, A. Wargenau, U. Brandt, M. Rohde, S. Dietrich, A. Kwade, A. Fleisner, The role of initial spore adhesion in pellet and biofilm formation in Aspergillus niger, Fungal genetics and biology 49 (1) (2012) 30-38.

[55] H.A. Wösten, Hydrophobins: multipurpose proteins, Annu. Rev. Microbiol. 55 (1) (2001) 625-646.

[56] K. Inoue, H. Kitaoka, P. Park, K. Ikeda, Novel aspects of hydrophobins in wheat isolate of Magnaporthe oryzae: Mpg1, but not Mhp1, is essential for adhesion and pathogenicity, J. Gen. Plant Pathol. 82 (1) (2016) 18-28.

[57] N.J. Talbot, M.J. Kershaw, G.E. Wakley, O.M. De Vries, J.G. Wessels, J.E. Hamer, MPG1 encodes a fungal hydrophobin involved in surface interactions during infection-related development of Magnaporthe grisea, Plant Cell 8 (6) (1996) 985-999.

[58] S. Scherrer, O.M. De Vries, R. Dudler, J.G. Wessels, R. Honegger, Interfacial selfassembly of fungal hydrophobins of the lichen-forming ascomycetes Xanthoria parietina and X. ectaneoides, Fungal Genet. Biol. 30 (1) (2000) 81-93.

[59] J.G.H. Wessels, Hydrophobins, unique fungal proteins, Mycologist 14 (4) (2000) 153.

[60] H.A. Wösten, F.H. Schuren, J.G. Wessels, Interfacial self-assembly of a hydrophobin into an amphipathic protein membrane mediates fungal attachment to hydrophobic surfaces, EMBO J. 13 (24) (1994) 5848-5854.

[61] E. Dague, D. Alsteens, J.P. Latgé, Y.F. Dufrêne, High-resolution cell surface dynamics of germinating Aspergillus fumigatus conidia, Biophys. J. 94 (2) (2008) 656-660.

[62] S. Ott, Sexual reproduction and developmental adaptations in Xanthoria parietina, Nord. J. Bot. 7 (2) (1987) 219-228. 
[63] A.I. González-Ramírez, A. Ramírez-Granillo, M.G. Medina-Canales, A. V. Rodríguez-Tovar, M.A. Martínez-Rivera, Analysis and description of the stages of Aspergillus fumigatus biofilm formation using scanning electron microscopy, BMC Microbiol. 16 (1) (2016) 1-13.

[64] J. Meesen, S. Ott, Recognition mechanisms during the pre-contact state of lichens: I. Mycobiont-photobiont interactions of the mycobiont of Fulgensia bracteata, Symbiosis 59 (3) (2013) 121-130.

[65] S.R. Clayden, Thallus initiation and development in the lichen Rhizocarpon lecanorinum, New Phytol. 139 (4) (1998) 685-695.

[66] F. Li, M.J. Svarovsky, A.J. Karlsson, J.P. Wagner, K. Marchillo, P. Oshel, S. P. Palecek, Eap1p, an adhesin that mediates Candida albicans biofilm formation in vitro and in vivo, Eukaryotic cell 6 (6) (2007) 931-939.

[67] C.J. Nobile, J.E. Nett, D.R. Andes, A.P. Mitchell, Function of Candida albicans adhesin Hwp1 in biofilm formation, Eukaryot. Cell 5 (10) (2006) 1604-1610.

[68] A. Beauvais, C. Schmidt, S. Guadagnini, P. Roux, E. Perret, C. Henry, J.P. Latg'e, An extracellular matrix glues together the aerial-grown hyphae of Aspergillus fumigatus, Cellular microbiology 9 (6) (2007) 1588-1600.

[69] F.N. Gravelat, A. Beauvais, H. Liu, M.J. Lee, B.D. Snarr, D. Chen, M. Urb, Aspergillus galactosaminogalactan mediates adherence to host constituents and conceals hyphal $\beta$-glucan from the immune system, PLoS Pathog 9 (8) (2013), e1003575.

[70] I. Valsecchi, V. Dupres, E. Stephen-Victor, J.I. Guijarro, J. Gibbons, R. Beau, A. Beauvais, Role of hydrophobins in Aspergillus fumigatus, J. Fungi 4 (1) (2018) 2.

[71] J. Van Gestel, H. Vlamakis, R. Kolter, Division of labor in biofilms: the ecology of cell differentiation, Microbiol. Spectr. 3 (2015), MB-0002.

[72] D.G. Davies, M.R. Parsek, J.P. Pearson, B.H. Iglewski, J.W. Costerton, E. P. Greenberg, The involvement of cell-to-cell signals in the development of a bacterial biofilm, Science 280 (5361) (1998) 295-298.

[73] J.M. Hornby, E.C. Jensen, A.D. Lisec, J.J. Tasto, B. Jahnke, R. Shoemaker, K. W. Nickerson, Quorum sensing in the dimorphic fungus Candida albicans is mediated by farnesol, Appl. Environ. Microbiol. 67 (7) (2001) 2982-2992.

[74] M.A. Jabra-Rizk, M. Shirtliff, C. James, T. Meiller, Effect of farnesol on Candida dubliniensis biofilm formation and fluconazole resistance, FEMS Yeast Res. 6 (7) (2006) 1063-1073.

[75] G. Ramage, S.P. Saville, B.L. Wickes, J.L. López-Ribot, Inhibition of Candida albicans biofilm formation by farnesol, a quorum-sensing molecule, Appl. Environ. Microbiol. 68 (11) (2002) 5459-5463.

[76] G.S. Baillie, L.J. Douglas, Role of dimorphism in the development of Candida albicans biofilms, J. Med. Microbiol. 48 (7) (1999) 671-679.

[77] S. Fanning, A.P. Mitchell, Fungal biofilms, PLoS Pathog. 8 (4) (2012), e1002585.

[78] K.F. Mitchell, R. Zarnowski, D.R. Andes, Fungal super glue: the biofilm matrix and its composition, assembly, and functions, PLoS Pathog. 12 (9) (2016), e1005828. 
[79] E. Stocker-Wörgötter, R. Türk, Artificial resynthesis of thalli of the cyanobacterial lichen Peltigera praetextata under laboratory conditions, Lichenologist 23 (2) (1991) 127-138.

[80] R. Roth, R. Wagner, U. Goodenough, Lichen 3: outer layers, Algal Res. (2020). In this issue.

[81] Y. Wang, X. Wei, Z. Bian, J. Wei, J.R. Xu, Coregulation of dimorphism and symbiosis by cyclic AMP signaling in the lichenized fungus Umbilicaria muhlenbergii, Proc. Natl. Acad. Sci. 117 (38) (2020) 23847-23858.

[82] S.D. Harris, Branching of fungal hyphae: regulation, mechanisms and comparison with other branching systems, Mycologia 100 (6) (2008) 823-832.

[83] C.J. Barelle, M.L. Richard, C. Gaillardin, N.A. Gow, A.J. Brown, Candida albicans VAC8 is required for vacuolar inheritance and normal hyphal branching, Eukaryot. Cell 5 (2) (2006) 359-367.

[84] R.M. Donlan, J.W. Costerton, Biofilms: survival mechanisms of clinically relevant microorganisms, Clin. Microbiol. Rev. 15 (2) (2002) 167-193.

[85] Daniele Armaleo, Experimental microbiology of lichens: mycelia fragmentation, a novel growth chamber, and the origins of thallus differentiation, Symbiosis 11 (2-3) (1991) 163-177.

[86] S. Joneson, F. Lutzoni, Compatibility and thigmotropism in the lichen symbiosis: a reappraisal, Symbiosis 47 (2) (2009) 109-115.

[87] S. Joneson, D. Armaleo, F. Lutzoni, Fungal and algal gene expression in early developmental stages of lichen-symbiosis, Mycologia 103 (2) (2011) 291-306.

[88] V. Ahmadjian, Investigations on lichen synthesis, Am. J. Bot. 49 (3) (1962) 277-283.

[89] U. Goodenough, R. Wagner, R. Roth, Lichen 4: the algal layer, Algal Res. (2020). In this issue.

[90] R. Honegger, 15 the Symbiotic Phenotype of Lichen-forming Ascomycetes and Their Endo-and Epibionts, in: In Fungal associations (Pp. 287-339), Springer, Berlin, Heidelberg, 2012.

[91] L. Nybakken, K.A. Solhaug, W. Bilger, Y. Gauslaa, The lichens Xanthoria elegans and Cetraria islandica maintain a high protection against UV-B radiation in Arctic habitats, Oecologia 140 (2) (2004) 211-216.

[92] J.D. Lawrey, Chemical defense in lichen symbioses, in: Defensive Mutualism in Microbial Symbiosis, 2009, pp. 167-176.

[93] L. Hall-Stoodley, J.W. Costerton, P. Stoodley, Bacterial biofilms: from the natural environment to infectious diseases, Nat. Rev. Microbiol. 2 (2) (2004) 95.

[94] S.M. Hunt, E.M. Werner, B. Huang, M.A. Hamilton, P.S. Stewart, Hypothesis for the role of nutrient starvation in biofilm detachment, Appl. Environ. Microbiol. 70 (12) (2004) 7418-7425.

[95] J.Á. Kaplan, Biofilm dispersal: mechanisms, clinical implications, and potential therapeutic uses, J. Dent. Res. 89 (3) (2010) 205-218. 
[96] H. Dettki, P. Klintberg, P.A. Esseen, Are epiphytic lichens in young forests limited by local dispersal? Ecoscience 7 (3) (2000) 317-325.

[97] V. Ahmadjian, Artificial reestablishment of the lichen Cladonia cristatella, Science 151 (3707) (1966) 199-201.

[98] M. del Carmen Molina, A. Crespo, Comparison of development of axenic cultures of five species of lichen-forming fungi, Mycol. Res. 104 (5) (2000) 595-602.

[99] T.R. McDonald, E. Gaya, F. Lutzoni, Twenty-five cultures of lichenizing fungi available for experimental studies on symbiotic systems, Symbiosis 59 (3) (2013) 165-171.

[100] M.C. Molina, E. Stocker-Wörgötter, R. Türk, C. Vicente, Axenic culture of the mycobiont of Xanthoria parietina in different nutritive media effect of carbon source in spore germination, Endocytobiosis Cell Res. 12 (1997) $103-110$.

[101] I.V. Ene, R.J. Bennett, Hwp1 and related adhesins contribute to both mating and biofilm formation in Candida albicans, Eukaryot. Cell 8 (12) (2009) 1909-1913.

[102] D. Armaleo, O. Müller, F. Lutzoni, Ó.S. Andrésson, G. Blanc, H.B. Bode, S. Joneson, The lichen symbiosis re-viewed through the genomes of Cladonia grayi and its algal partner Asterochloris glomerata, BMC genomics 20 (1) (2019) 605.

[103] B. Schink, Energetics of syntrophic cooperation in methanogenic degradation, Microbiol. Mol. Biol. Rev. 61 (2) (1997) 262-280.

[104] M. Burmolle, D. Ren, T. Bjarnsholt, S.J. Sorensen, Interactions in multispecies biofilms: do they actually matter? Trends Microbiol. 22 (2) (2014) 84-91.

[105] L. Keller, M.G. Surette, Communication in bacteria: an ecological and evolutionary perspective, Nat. Rev. Microbiol. 4 (4) (2006) 249-258.

[106] D.A. Hogan, Å. Vik, R. Kolter, A Pseudomonas aeruginosa quorum-sensing molecule influences Candida albicans morphology, Mol. Microbiol. 54 (5) (2004) 1212-1223.

[107] R.J. Silverman, A.H. Nobbs, M.M. Vickerman, M.E. Barbour, H.F. Jenkinson, Interaction of Candida albicans cell wall Als3 protein with Streptococcus gordonii SspB adhesin promotes development of mixed-species communities, Infect. Immun. 78 (11) (2010) 4644-4652.

[108] C. Cugini, M.W. Calfee, J.M. Farrow III, D.K. Morales, E.C. Pesci, D.A. Hogan, Farnesol, a common sesquiterpene, inhibits PQS production in Pseudomonas aeruginosa, Mol. Microbiol. 65 (4) (2007) 896-906.

[109] C.V. Bamford, A. d'Mello, A.H. Nobbs, L.C. Dutton, M.M. Vickerman, H. F. Jenkinson, Streptococcus gordonii modulates Candida albicans biofilm formation through intergeneric communication, Infect. Immun. 77 (9) (2009) 3696-3704.

[110] M. Khasin, R.R. Cahoon, K.W. Nickerson, W.R. Riekhof, Molecular machinery of auxin synthesis, secretion, and perception in the unicellular chlorophyte alga Chlorella sorokiniana UTEX 1230, PLoS One 13 (12) (2018), e0205227. 
[111] B. Gökalsın, N.C. Sesal, Lichen secondary metabolite evernic acid as potential quorum sensing inhibitor against Pseudomonas aeruginosa, World J. Microbiol. Biotechnol. 32 (9) (2016) 150.

[112] P. Nithyanand, R.M.B. Shafreen, S. Muthamil, S.K. Pandian, Usnic acid, a lichen secondary metabolite inhibits Group A Streptococcus biofilms, Antonie Van Leeuwenhoek 107 (1) (2015) 263-272.

[113] R.S. Singh, A.K. Walia, Characteristics of lichen lectins and their role in symbiosis, Symbiosis 62 (3) (2014) 123-134.

[114] U. Rutishauser, L. Sachs, Cell-to-cell binding induced by different lectins, J. Cell Biol. 65 (2) (1975) 247-257.

[115] R. Yahr, R. Vilgalys, P.T. Depriest, Strong fungal specificity and selectivity for algal symbionts in Florida scrub Cladonia lichens, Mol. Ecol. 13 (11) (2004) 3367-3378.

[116] F.M. Fox, Ultrastructure of mycelial strands of Leccinum scabrum, ectomycorrhizal on birch (Betula spp.), Trans. Br. Mycol. Soc. 89 (4) (1987) 551-560.

[117] M.W. Harding, L.L. Marques, R.J. Howard, M.E. Olson, Can filamentous fungi form biofilms? Trends Microbiol. 17 (11) (2009) 475-480.

[118] J. Felten, A. Kohler, E. Morin, R.P. Bhalerao, K. Palme, F. Martin, V. Legué, The ectomycorrhizal fungus Laccaria bicolor stimulates lateral root formation in poplar and Arabidopsis through auxin transport and signaling, Plant Physiology 151 (4) (2009) 1991-2005.

[119] K. Akiyama, K.I. Matsuzaki, H. Hayashi, Plant sesquiterpenes induce hyphal branching in arbuscular mycorrhizal fungi, Nature 435 (7043) (2005) 824.

[120] M.T. Hanlon, C. Coenen, Genetic evidence for auxin involvement in arbuscular mycorrhiza initiation, New Phytol. 189 (3) (2011) 701-709.

[121] A. Sirrenberg, C. Göbel, S. Grond, N. Czempinski, A. Ratzinger, P. Karlovsky, K. Pawlowski, Piriformospora indica affects plant growth by auxin production, Physiologia plantarum 131 (4) (2007) 581-589.

[122] D.H. Richardson, War in the world of lichens: parasitism and symbiosis as exemplified by lichens and lichenicolous fungi, Mycol. Res. 103 (6) (1999) 641-650.

[123] J.R. Herr, M. "Opik, D.S. Hibbett, Towards the unification of sequencebased classification and sequence-based identification of host-associated microorganisms, New Phytol. 205 (1) (2015) 27-31.

[124] H.C. Flemming, J. Wingender, The biofilm matrix, Nat. Rev. Microbiol. 8 (9) (2010) 623.

[125] S. Arnaouteli, C.E. MacPhee, N.R. Stanley-Wall, Just in case it rains: building a hydrophobic biofilm the Bacillus subtilis way, Curr. Opin. Microbiol. 34 (2016) 7-12.

[126] G.M. Bruinsma, H.C. Van der Mei, H.J. Busscher, Bacterial adhesion to surface hydrophilic and hydrophobic contact lenses, Biomaterials 22 (24) (2001) 3217-3224. 
[127] T. Spribille, G. Tagirdzhanova, S. Goyette, V. Tuovinen, R. Case, W.F. Zandberg, 3D biofilms: in search of the polysaccharides holding together lichen symbioses, FEMS Microbiol. Lett. 367 (5) (2020), fnaa023.

[128] E.S. Antonova, B.K. Hammer, Quorum-sensing autoinducer molecules produced by members of a multispecies biofilm promote horizontal gene transfer to Vibrio cholerae, FEMS Microbiol. Lett. 322 (1) (2011) 68-76.

[129] A. Beck, P.K. Divakar, N. Zhang, M.C. Molina, L. Struwe, Evidence of ancient horizontal gene transfer between fungi and the terrestrial alga Trebouxia, Org. Divers. Evol. 15 (2) (2015) 235-248.

[130] F.C. Carniel, M. Gerdol, A. Montagner, E. Banchi, G. De Moro, C. Manfrin, $M$. Tretiach, New features of desiccation tolerance in the lichen photobiont Trebouxia gelatinosa are revealed by a transcriptomic approach, Plant Molecular Biology 91 (3) (2016) 319-339.

[131] T.R. McDonald, F.S. Dietrich, F. Lutzoni, Multiple horizontal gene transfers of ammonium transporters/ammonia permeases from prokaryotes to eukaryotes: toward a new functional and evolutionary classification, Mol. Biol. Evol. 29 (1) (2012) 51-60.

[132] E. Mowat, C. Williams, B. Jones, S. McChlery, G. Ramage, The characteristics of Aspergillus fumigatus mycetoma development: is this a biofilm? Med. Mycol. 47 (Supplement 1) (2009) S120-S126.

[133] P.S. Stewart, J.W. Costerton, Antibiotic resistance of bacteria in biofilms, Lancet 358 (9276) (2001) 135-138.

[134] K. Lewis, Riddle of biofilm resistance, Antimicrob. Agents Chemother. 45 (4) (2001) 999-1007.

[135] T.F.C. Mah, G.A. O'Toole, Mechanisms of biofilm resistance to antimicrobial agents, Trends Microbiol. 9 (1) (2001) 34-39.

[136] H.C. Flemming, Biofilms and environmental protection, Water Sci. Technol. 27 (7-8) (1993) 1-10.

[137] J. Meesen, F.J. Sánchez, A. Brandt, E.M. Balzer, R. de la Torre, L.G. Sancho, S. Ott, Extremotolerance and resistance of lichens: comparative studies on five species used in astrobiological research I. Morphological and anatomical characteristics, Orig. Life Evol. Biosph. 43 (3) (2013) 283-303.

[138] S. Onofri, R. de la Torre, J.P. de Vera, S. Ott, L. Zucconi, L. Selbmann, G. Horneck, Survival of rock-colonizing organisms after 1.5 years in outer space, Astrobiology 12 (5) (2012) 508-516.

[139] L.G. Sancho, R. De la Torre, G. Horneck, C. Ascaso, A. de los Rios, A. Pintado, M. Schuster, Lichens survive in space: results from the 2005 LICHENS experiment, Astrobiology 7 (3) (2007) 443-454.

[140] G.S. Baillie, L.J. Douglas, Matrix polymers of Candida biofilms and their possible role in biofilm resistance to antifungal agents, J. Antimicrob. Chemother. 46 (3) (2000) 397-403.

[141] P. Gilbert, J. Das, I. Foley, Biofilm susceptibility to antimicrobials, Adv. Dent. Res. 11 (1) (1997) 160-167. 
[142] G. Sarret, A. Manceau, D. Cuny, C. Van Haluwyn, S. Déruelle, J.L. Hazemann, J. J. Menthonnex, Mechanisms of lichen resistance to metallic pollution, Environ. Sci. Technol. 32 (21) (1998) 3325-3330.

[143] E. Skye, Lichens as biological indicators of air pollution, Annu. Rev. Phytopathol. 17 (1) (1979) 325-341.

[144] K. Szczepaniak, M. Biziuk, Aspects of the biomonitoring studies using mosses and lichens as indicators of metal pollution, Environ. Res. 93 (3) (2003) 221-230.

[145] F. Ekmekyapar, A. Aslan, Y.K. Bayhan, A. Cakici, Biosorption of copper (II) by nonliving lichen biomass of Cladonia rangiformis hoffm, J. Hazard. Mater. 137 (1) (2006) 293-298.

[146] G.M. Gadd, Metals, minerals and microbes: geomicrobiology and bioremediation, Microbiology 156 (3) (2010) 609-643.

[147] Y.B. Huang, W.H. Wang, A. Peng, Accumulation of Cu (II) and Pb (II) by biofilms grown on particulate in aquatic systems, J. Environ. Sci. Health A 35 (4) (2000) 575-592.

[148] G.M. Teitzel, M.R. Parsek, Heavy metal resistance of biofilm and planktonic Pseudomonas aeruginosa, Appl. Environ. Microbiol. 69 (4) (2003) 2313-2320.

[149] S.K. Kazy, P. Sar, S.P. Singh, A.K. Sen, S. D'souza, Extracellular polysaccharides of a copper-sensitive and a copper-resistant Pseudomonas aeruginosa strain: synthesis, chemical nature and copper binding, World J. Microbiol. Biotechnol. 18 (6) (2002) 583-588.

[150] J.J. Harrison, H. Ceri, R.J. Turner, Multimetal resistance and tolerance in microbial biofilms, Nat. Rev. Microbiol. 5 (12) (2007) 928.

[151] O.D. Uluozlu, A. Sari, M. Tuzen, M. Soylak, Biosorption of Pb (II) and Cr (III) from aqueous solution by lichen (Parmelina tiliaceae) biomass, Bioresour. Technol. 99 (8) (2008) 2972-2980.

[152] Y. Matsumura, H.N. Ananthaswamy, Toxic effects of ultraviolet radiation on the skin, Toxicol. Appl. Pharmacol. 195 (3) (2004) 298-308.

[153] R.P. Rastogi, A. Kumar, M.B. Tyagi, R.P. Sinha, Molecular mechanisms of ultraviolet radiation-induced DNA damage and repair, J. Nucleic Acids (2010) 2010.

[154] K.A. Solhaug, Y. Gauslaa, L. Nybakken, W. Bilger, UV-induction of sunscreening pigments in lichens, New Phytol. 158 (1) (2003) 91-100.

[155] K.H. Nguyen, M. Chollet-Krugler, N. Gouault, S. Tomasi, UV-protectant metabolites from lichens and their symbiotic partners, Nat. Prod. Rep. 30 (12) (2013) 1490-1508.

[156] M. McEvoy, L. Nybakken, K.A. Solhaug, Y. Gauslaa, UV triggers the synthesis of the widely distributed secondary lichen compound usnic acid, Mycol. Prog. 5 (4) (2006) 221-229.

[157] M.O. Elasri, R.V. Miller, Study of the response of a biofilm bacterial community to UV radiation, Appl. Environ. Microbiol. 65 (5) (1999) 2025-2031. 
[158] V.F. Zenoff, F. Siñeriz, M.E. Farias, Diverse responses to UV-B radiation and repair mechanisms of bacteria isolated from high-altitude aquatic environments, Appl. Environ. Microbiol. 72 (12) (2006) 7857-7863.

[159] M. Ragon, G. Restoux, D. Moreira, A.P. Moller, P. López-García, Sunlightexposed biofilm microbial communities are naturally resistant to Chernobyl ionizing-radiation levels, PLoS One 6 (7) (2011), e21764.

[160] I. Kranner, R. Beckett, A. Hochman, T.H. Nash III, Desiccation-tolerance in lichens: a review, Bryologist (2008) 576-593.

[161] T. Ophir, D.L. Gutnick, A role for exopolysaccharides in the protection of microorganisms from desiccation, Appl. Environ. Microbiol. 60 (2) (1994) 740-745.

[162] W.S. Chang, M. Van De Mortel, L. Nielsen, G.N. De Guzman, X. Li, L.J. Halverson, Alginate production by Pseudomonas putida creates a hydrated microenvironment and contributes to biofilm architecture and stress tolerance under water-limiting conditions, J. Bacteriol. 189 (22) (2007) 8290-8299.

[167] D. Lebeaux, J.M. Ghigo, C. Beloin, Biofilm-related infections: bridging the gap between clinical management and fundamental aspects of recalcitrance toward antibiotics, Microbiol. Mol. Biol. Rev. 78 (3) (2014) 510-543.

[168] A.P. Roberts, J. Pratten, M. Wilson, P. Mullany, Transfer of a conjugative transposon, Tn 5397 in a model oral biofilm, FEMS Microbiol. Lett. 177 (1) (1999) 63-66.

[169] Norio Yamamura, Vertical transmission and evolution of mutualism from parasitism, Theoretical Population Biology 44 (1) (1993) 95-109, https://doi. org/10.1006/tpbi.1993.1020

[170] Rosemarie Honegger, Metabolic interactions at the mycobiont-photobiont interface in lichens. The Mycota: Plant Relationships 5, Springer, Berlin, 1997, pp. 209-221.

[171] Rosemarie Honegger, Cytological aspects of the mycobiont-phycobiont relationship in Lichens, The Lichenologist 16 (2) (1984) 111-127, https://doi. org/10.1017/S0024282984000293 